\title{
Progestin-only contraceptives: effects on weight
}

\author{
Laureen M Lopez ${ }^{1}$, Alison Edelman ${ }^{2}$, Mario Chen $^{3}$, Conrad Otterness ${ }^{4}$, James Trussell ${ }^{5}$, \\ and Frans M Helmerhorst ${ }^{6}$
}

${ }^{1}$ Clinical Sciences, FHI 360, Research Triangle Park, North Carolina, USA ${ }^{2}$ Dept. of Obstetrics and Gynecology, Oregon Health \& Science University, Portland, Oregon, USA ${ }^{3}$ Division of Biostatistics, FHI 360, Research Triangle Park, North Carolina, USA ${ }^{4}$ Global Health Access Program, Mae Sot, Thailand ${ }^{5}$ Office of Population research, Princeton University, Princeton, New Jersey, USA ${ }^{6}$ Department of Gynaecology, Division of Reproductive Medicine and Dept. of Clinical Epidemiology, Leiden University Medical Center, Leiden, Netherlands

\section{Abstract}

Background-Progestin-only contraceptives (POCs) are appropriate for many women who cannot or should not take estrogen. Many POCs are long-acting, cost-effective methods of preventing pregnancy. However, concern about weight gain can deter the initiation of contraceptives and cause early discontinuation among users.

Objectives-The primary objective was to evaluate the association between progestin-only contraceptive use and changes in body weight.

Search methods-Through May 2013, we searched MEDLINE, CENTRAL, POPLINE, LILACS, ClinicalTrials.gov, and ICTRP. The 2010 search also included EMBASE. For the initial review, we contacted investigators to identify other trials.

Selection criteria-All comparative studies were eligible that examined a POC versus another contraceptive method or no contraceptive. The primary outcome was mean change in body weight or mean change in body composition. We also considered the dichotomous outcome of loss or gain of a specified amount of weight.

Data collection and analysis-Two authors extracted the data. We computed the mean difference (MD) with 95\% confidence interval (CI) for continuous variables. For dichotomous outcomes, the Mantel-Haenszel odds ratio (OR) with 95\% CI was calculated.

Main results-We found 16 studies; one examined progestin-only pills, one studied the levonorgestrel-releasing intrauterine system (LNG-IUS), four examined an implant, and 10 focused on depot medroxyprogesterone acetate (DMPA). Outcomes examined were changes in body weight only (14 studies), changes in both body weight and body composition (1 study), and

Contact person: Laureen M Lopez, Clinical Sciences, FHI 360, P.O. Box 13950, Research Triangle Park North Carolina 27709, USA, llopez@fhi360.org.

\section{Contributions of authors}

For the initial review, L Lopez reviewed the search results, extracted and entered the data, and drafted the review. For the 2013 update, C Otterness reviewed the search results, did the primary data extraction and entering, and incorporated the new study. L Lopez did the second data extraction and updated the text in 2013. A Edelman and F Helmerhorst helped with the second data extraction for the initial review. M Chen provided guidance on study design, data analysis, and interpretation of results for the initial review and the 2013 update. All authors reviewed and commented on the document.

Declarations of interest

The authors do not have any conflicts of interest to declare regarding this review. 
changes in body composition only ( 1 study). We did not conduct meta-analysis due to the various contraceptive methods and weight change measures.

Comparison groups did not differ significantly for weight change in 12 studies. However, three studies showed weight change differences for POC users compared to women not using a hormonal method. In one study, weight gain $(\mathrm{kg})$ was greater for the DMPA group than the group using a non-hormonal IUD in years one through three [(MD 2.28; 95\% CI 1.79 to 2.77), (MD $2.71,95 \%$ CI 2.12 to 3.30), and (MD 3.17; 95\% CI 2.51 to 3.83), respectively]. The differences were notable within the normal weight and overweight subgroups. Two implant studies also showed differences in weight change. The implant group (six-capsule) had greater weight gain $(\mathrm{kg})$ compared to the group using a non-hormonal IUD in both studies [(MD 0.47 (95\% CI 0.29 to 0.65); (MD 1.10; 95\% CI 0.36 to 1.84)]. In one of those studies, the implant group also had greater weight gain than a group using a barrier method or no contraceptive (MD 0.74; 95\% CI 0.52 to 0.96).

The two studies that assessed body composition change showed differences between POC users and women not using a hormonal method. Adolescents using DMPA had a greater increase in body fat $(\%)$ compared to a group not using a hormonal method (MD 11.00; 95\% CI 2.64 to 19.36). The DMPA group also had a greater decrease in lean body mass (\%) (MD -4.00; $95 \%$ CI -6.93 to -1.07$)$. The other study reported differences between an LNG-IUS group and a nonhormonal IUD group in percent change in body fat mass $(2.5 \%$ versus $-1.3 \%$, respectively; reported $\mathrm{P}$ value $=0.029)$ and percent change in lean body mass $(-1.4 \%$ versus $1.0 \%$, respectively; reported $\mathrm{P}$ value $=0.027$ ).

Authors' conclusions-The overall quality of evidence was moderate to low, given that the studies were evenly divided across the evidence quality groups (high, moderate, low, or very low quality). We found limited evidence of weight gain when using POCs. Mean gain was less than 2 $\mathrm{kg}$ for most studies up to 12 months. Weight change for the POC group generally did not differ significantly from that of the comparison group using another contraceptive. Two studies that assessed body composition showed that POC users had greater increases in body fat and decreases in lean body mass compared to users of non-hormonal methods. Appropriate counseling about typical weight gain may help reduce discontinuation of contraceptives due to perceptions of weight gain.

\section{Plain language summary}

\section{Effects of progestin-only birth control on weight}

Progestin-only contraceptives (POCs) can be used by women who cannot or should not take the hormone estrogen. Many POCs are long acting, cost less than some other methods, and work well to prevent pregnancy. Some people worry that weight gain is a side effect of these birth control methods. Concern about weight gain can keep women from using these methods, or cause women to stop using them early, which can lead to unplanned pregnancy. We looked at studies of POCs and changes in body weight.

Through May 2013, we did computer searches for studies of progestin-only birth control compared to another birth control method or no contraceptive. We also wrote to researchers to find other trials. The focus was on change in body weight.

We found 16 studies. Three showed differences in weight gain change for POC users compared to women who did not use hormonal birth control. In one study, the group using the injectable 'depo' gained more weight by one, two, and three years compared to a group using a non-hormonal IUD. The difference was noted among the normal weight and overweight women. Two studies showed an implant group (six-capsule) had more weight 
gain than the group using a non-hormonal IUD. In one study, the implant group also gained more weight than a group using a barrier method or no birth control.

Two studies showed differences in body mass change. In one, the depo group had a greater increase in body fat than a group with no hormonal birth control. The depo group also had a greater decrease in lean body mass than the no-hormonal group. The other study reported differences between users of the levonorgestrel intrauterine system (LNG-IUS) and those who used a non-hormonal IUD. The LNG-IUS group had an increase in body fat mass and a decrease in lean body mass

We found little evidence of weight gain when using POCs. Mean weight gain was less than $2 \mathrm{~kg}$ for most studies up to 12 months. The groups using other birth control methods had about the same weight gain. The two studies of body mass showed POC users had greater increases in body fat and decreases in lean mass than users of non-hormonal methods. Good counseling about typical weight gain may help women avoid stopping birth control early due to worries about weight gain.

\section{Background}

\section{Description of the condition}

Weight gain is often considered a side effect of using hormonal contraceptives (Bartz 2011; Raymond 2011). This perception may be based on self-report of side effects rather than actual weight changes (Paul 1997; Berenson 2008). A Cochrane review revealed no clear evidence of weight gain with the use of combined hormonal contraceptives (Gallo 2011). Many clinicians and women also believe that progestin-only contraceptives cause weight gain (FWHC 2010; WebMD 2010).

Concern about weight gain can deter the initiation of contraceptives and cause early discontinuation among users. In a United States (US) study of bone mineral density, weight gain was reported more often by women using depot medroxyprogesterone acetate (DMPA) than those using a low-dose oral contraceptive (Berenson 2008). A national study in New Zealand found that weight gain was the most common side effect reported with DMPA use after menstrual disturbances (Paul 1997). In the US, weight gain has been reported to be a major reason for discontinuing DMPA use (Bonny 2004). Some evidence suggests that DMPA is a concern for adolescents who are already obese (Curtis 2009). Levonorgestrel implants have also been implicated for weight gain (Sivin 2003). The gain may be greater among women in the US than among those in China, and may be partly attributable to differences in dietary habits. In US studies, half of all implant discontinuations were attributed to the side effects of headache, weight, and mood changes (Sivin 2003).

\section{Description of the intervention}

Progestin-only contraceptives (POCs) do not contain estrogen, unlike combined hormonal contraceptives that have both progestin and estrogen. Therefore, POCs are appropriate for women who cannot or should not take estrogen (ACOG 2006). The World Health Organization classes POCs as category 1 for women who are obese (body mass index $>=30$ $\mathrm{kg} / \mathrm{m}^{2}$ ). Category 1 is a condition with no restriction for use of the contraceptive method. For obese adolescents, DMPA is category 2 due to possible effects on bone mineral density (WHO 2010). For category 2, method advantages generally outweigh the theoretical or proven risks. POCs are also category 1 for breastfeeding women who are at least six weeks postpartum (WHO 2010), while combined hormonal contraceptives are category 3 for such women. 
Oral contraceptives are the most commonly used reversible method in more developed areas of the world at $18 \%$ (UN 2011), and include combined oral contraceptives (COCs) as well as progestin-only pills (POPs) (Grimes 2010). The introduction of a new progestin-only oral contraceptive in Europe (Faculty of Family Planning 2003) led to renewed interest in this class of oral contraceptives. Use of intrauterine devices (IUDs) leads in less developed areas at $15 \%$, but hormonal IUDs are not widely used. Next in usage are oral contraceptives (7\%), injectables (4\%) and implants (0.4\%) (UN 2011). Some injectable contraceptives are combined, i.e., contain estrogen and progestin, while others like DMPA are progestin-only.

Injectables, implants, and the hormonal intrauterine system (IUS) are long-acting, thus freeing women from daily action to prevent unintended pregnancy. Long-acting methods are among the most cost-effective contraceptives in many areas. Studies of long-acting contraceptives are often of longer duration than those for combined oral contraceptives (COCs), making study of weight change over time more feasible.

\section{How the intervention might work}

In general, weight gain is due to an increase in one or more factors: fluid retention, muscle mass, and fat deposition. An early mechanistic study of DMPA and weight gain found no significant changes in fluid compartmental size, creatinine excretion rate, or nitrogen metabolism (Amatayakul 1980). The researchers reported an association between skinfold thickness and weight gain, indicating the gain was related to increased body fat. A study of risk factors for weight gain among adolescent DMPA users showed that appetite decreased while on DMPA (Bonny 2004). However, a brief randomized controlled trial (RCT) of DMPA versus placebo examined energy intake and expenditure as well as weight gain (Pelkman 2001). Meals were provided along with a range of snacks. Menstrual phase (pretreatment) was associated with differences in energy intake and expenditure, but DMPA did not affect intake, expenditure, or weight gain.

The possible causal association between contraceptives and weight gain is difficult to study. During adolescence, some weight gain is developmentally normal and appropriate. Also, people tend to gain weight over time (Flegal 2000). No consensus exists regarding what is excessive weight gain. Ideally, studies would define a clinically important weight gain a priori, but weight change is rarely a primary outcome in contraceptive studies.

Examining contraceptive use and weight gain can be complicated by the initial weight of the users. We know little about how overweight women metabolize hormonal contraceptives, since many studies exclude overweight women (Edelman 2009; Lopez 2012). Further, concern about contraceptive effectiveness among overweight women (Grimes 2005; Trussell 2009) may lead to different usage by women of greater body weight. Some contraceptive methods that require a medical procedure have been associated with body weight. Among obese women in a US survey of contraceptive use (Schraudenbach 2009), tubal ligation was similar to pill use at nearly $26 \%$. Among groups with lower body mass index (BMI), the figures were $13.5 \%$ and $19.5 \%$, respectively. Implant use was relatively low overall, but higher among overweight $(0.9 \%)$ and obese women (1.2\%) than among normal or underweight women $(0.4 \%)$. IUD use ranged from $4.1 \%$ to $4.6 \%$ across the BMI groups. In contrast, within an RCT focused on postpartum weight reduction, women with a BMI of 35 or higher were less likely to use 'effective' contraceptive than those with a BMI less than 30 (Chin 2009). Effective contraception referred to hormonal methods, IUDs, or sterilization.

\section{Why it is important to do this review}

Currently no comprehensive systematic review exists on progestin-only contraceptives and weight change. Concern about weight gain might deter women from using these effective 
contraceptives and health care providers from recommending them. We are not examining effectiveness nor focusing on overweight women. Many reviews have examined effectiveness of specific progestin-only contraceptives, such as progestin-only pills (Grimes 2010) and IUDs (Grimes 2007). Further, a Cochrane review examined effectiveness of hormonal contraceptives for overweight women versus women who were not overweight (Lopez 2013).

Progestin-only contraceptives are an attractive option for many women. The cost can be less than that of COCs in some areas, and many postpartum women can use them. Further, POCs are appropriate for many obese women, an important factor given the worldwide epidemic of obesity (Ogden 2007; Prentice 2006; Flegal 2012).

\section{Objectives}

The primary objective was to evaluate the potential association between progestin-only contraceptive use and changes in body weight.

\section{Methods}

\section{Criteria for considering studies for this review}

Types of studies-We included studies that examined progestin-only contraceptives used for contraception and their associations with weight change. Reports had to contain information on the specific contraceptive method(s) examined. We searched for studies with comparative data on a progestin-only contraceptive versus another contraceptive (differing in formulation, dose, or regimen) or no contraceptive. This includes comparisons of a progestin-only contraceptive with a combination contraceptive as well as comparisons of two different types of progestin-only contraceptives.

We eliminated studies focused on women with specific health problems, such as diabetes or HIV. We also excluded studies of contraceptives as treatment for specific disorders, e.g., acne, hirsutism, or polycystic ovary syndrome.

Types of participants-Participants were the women in the studies who used the progestin-only contraceptive for contraception or who had the comparison intervention or placebo.

Types of interventions-Any progestin-only contraceptive could have been examined, such as an oral contraceptive, an injectable, an implant, or the hormonal intrauterine system (IUS). Treatment duration must have been at least three cycles.

Progestin method of interest must have been specified and not combined in a group with another method, e.g., a group that used either DMPA or norethisterone enanthate (NET-EN). The comparison could have been another progestin-only contraceptive or a group of contraceptives, such as COCs. We did not include comparison groups identified only as OC users, since the oral contraceptives could have been progestin-only pills or combined oral contraceptives.

Types of outcome measures-The primary outcome was the continuous outcome of mean change in body weight, BMI, or body composition (e.g., percent body fat) over time with the use of progestin-only contraceptives. If mean change in body weight or BMI was not available per study arm, we examined the dichotomous outcome of loss or gain of a specified amount of weight in each study arm. Measured weight was used (not self-reported weight). 
We excluded studies that did not report change data but only reported mean weight or BMI at pre- and post-treatment.

\section{Search methods for identification of studies}

Electronic searches-Through May 2013, we searched MEDLINE, Cochrane Central Register of Controlled Trials (CENTRAL), POPLINE, and LILACS. We also searched for trials via ClinicalTrials.gov and the search portal of the International Clinical Trials Registry Platform (ICTRP). The 2013 search strategies are shown in Appendix 1. The 2010 search also included EMBASE; strategies can be found in Appendix 2.

Searching other resources-We examined reference lists of relevant articles and contacted investigators in the field to seek additional unpublished trials or published trials.

\section{Data collection and analysis}

Selection of studies-We assessed for inclusion all titles and abstracts identified during the literature searches. One author reviewed the search results and identified reports for inclusion or exclusion. A second author also examined the reports identified for appropriate categorization according to the criteria above.

All comparative study designs were considered. For example, studies could have been randomized controlled trials (RCTs), other prospective studies (provided intervention; assignment not random), observational studies of existing contraceptive users, case-control studies, or retrospective chart reviews. Post hoc analysis from any of these types of studies was also considered. However, the studies had to meet the other Criteria for considering studies for this review.

Data extraction and management-One author abstracted the data and entered the information into RevMan. Another author conducted a second data abstraction and verified correct data entry. Any discrepancies were resolved by discussion or with a third author if necessary.

Assessment of risk of bias in included studies-The randomized controlled trials were examined for methodological quality, according to recommended principles (Higgins 2011). Methodology considered included randomization method, allocation concealment, blinding, and losses to follow up and early discontinuation. Adequate methods for allocation concealment include a centralized telephone system and the use of sequentially-numbered, opaque, sealed envelopes (Schulz 2002). In addition, high losses to follow up threaten validity (Strauss 2005).

To assess the non-randomized data, we used the principles outlined in section 13.5 of Higgins 2011 as well as the STROBE statement for reports of observational studies (Von Elm 2007). We assessed whether the analysis included adjustment for potential confounding related to weight change. The study groups could differ in ways related to the outcome, such as initial weight or BMI or previous use of hormonal contraceptives.

For all studies, limitations in design were presented in Risk of bias in included studies and were considered when interpreting the results.

Measures of treatment effect-Outcomes listed in Characteristics of included studies are focused on those relevant to this review. For weight gain measure with follow up of less than one year, we selected the last date. If multiple time points were reported up to one year, 
we used the midpoint and the one-year data. If data were available for more than three years, we used one-year data as well as the midpoint and the last measure.

We examined results by the contraceptive method studied, e.g., injectable or implant, as well as by formulation, dose, or regimen as appropriate. The main comparisons for this review were between users of progestin-only contraceptives and users of another contraceptive (differing in formulation, dose, or regimen) or no hormonal contraceptive.

With nonrandomized studies, researchers need to control for confounding factors. We considered adjusted measures and the results of matched analysis from paired samples. Investigators may have used a variety of adjustment strategies. We specified whether confounding was considered in the design (e.g., matching, stratification). We provide the confounding factors considered in the design and analysis when presenting results. Where available, results of adjusted or matched analysis are presented as reported by the researchers. For unadjusted continuous outcomes, the mean difference was computed with 95\% confidence interval (CI) using a fixed-effect model. RevMan uses the inverse variance approach (Higgins 2011). Continuous measures include mean change in weight, BMI, and percentage body fat. For dichotomous outcomes, the Mantel-Haenszel odds ratio (OR) with 95\% CI was calculated using a fixed-effect model. An example is the proportion of women who gained a specified amount of weight. Fixed and random effects give the same result if no heterogeneity exists, as when a comparison includes only one study.

Dealing with missing data-We excluded studies with insufficient data on weight or BMI for analysis in this review. Reports sometimes provided results in figures without specific numbers; others presented means without any variance estimate. Many studies were more than 10 years old, making it difficult to obtain additional data from the researchers.

Assessment of heterogeneity-We expected study populations, designs, and interventions to be heterogeneous. We described the clinical and methodological diversity (or heterogeneity) of the studies. We did not pool data from studies that had different contraceptive methods (e.g., DMPA or implants), different doses of the same method, or different criteria for reporting weight change. Therefore, we were not able to conduct metaanalysis due to the range of contraceptive methods examined and different reporting for weight change. Heterogeneity is not an issue when a comparison has a single study.

Data synthesis-Data were not available to examine weight change in relation to age. A certain amount of weight gain is part of normal development for adolescents. Studies that targeted adolescents are identified. Studies that included both adolescents and adult women did not provide outcome data for age subgroups.

When data were available, we also examined weight change in relation to initial body weight or body mass index (BMI) [weight $(\mathrm{kg}) /$ height $\left.(\mathrm{m})^{2}\right]$. Weight change may differ for women who were initially overweight or obese versus those who were not overweight or obese. We preferred BMI over weight alone, as a higher BMI generally reflects more body fat (CDC 2012). However, the measures and cutoffs depended on those used in the included studies. Frequently used BMI categories are 25 to $29.9\left(\mathrm{~kg} / \mathrm{m}^{2}\right)$ for overweight and 30 or higher for obesity (CDC 2012). We also considered studies that used older US cutoffs derived from the National Health and Nutrition Examination Survey II (NHANES II) conducted from 1976 to 1980 (Najjar 1987). From NHANES II, the BMI cutoffs for women are 27.3 for overweight and 32 for obesity.

After conducting the review, we assessed the quality of evidence using the GRADE approach (Higgins 2011). Grades could be high, moderate, low, or very low. The initial 
grade was based on study design: RCTs were considered to provide high quality evidence; prospective non-randomized studies, moderate quality; and retrospective studies, low quality. The initial rating was downgraded a level for each of the following: a) losses to follow up of $25 \%$ or more and b) inappropriate exclusions after randomization.

Sensitivity analysis-We conducted sensitivity analysis by removing the retrospective studies, i.e., chart reviews. The remaining prospective studies included RCTs, other prospective designs, and post hoc analysis of data from prospective studies. Further, we examined results after removing studies that had losses or discontinuations totaling $25 \%$ or more of the sample.

\section{Main results}

\section{Description of studies}

Results of the search-The 2013 search produced 189 citations: 123 references from the database searches, 63 trials from searches of the clinical trials sites, and 3 from other sources. One new study was included (Dal'Ava 2012). After reviewing the full text, we excluded five studies (Bahamondes 2010; Chen 2011; Costa 2012; Kaunitz 2009; SegallGutierrez 2012) and two secondary articles from previously excluded studies (Berenson 2009; Bonny 2006). The remaining references were discarded after reviewing the titles and abstracts. From the clinical trials sites, three new trials were added to Ongoing studies.

Included studies-Sixteen studies met our inclusion criteria. Ten prospective studies included five RCTs (WHO 1983; Salem 1988; Ball 1991; Sivin 1998; Westhoff 2007) and five with other prospective designs (Tankeyoon 1976; Castle 1978; Salem 1984; Bonny 2009; Dal'Ava 2012). Six studies used retrospective data (Moore 1995; Taneepanichskul 1998; Espey 2000; Sule 2005; Tuchman 2005; Pantoja 2010).

The progestin-only contraceptives examined were as follows:

- Oral contraceptives (OCs) containing norethisterone $350 \mu \mathrm{g}$ or levonorgestrel $30 \mu \mathrm{g}$

- Injectable: depot medroxyprogesterone acetate (DMPA) $150 \mathrm{mg} / \mathrm{mL}$ or $450 \mathrm{mg} / \mathrm{mL}$ (intramuscular) or $104 \mathrm{mg} / 0.65 \mathrm{~mL}$ (subcutaneous)

- Injectable: norethisterone enanthate (NET-EN) $200 \mathrm{mg}$

- Implants (levonorgestrel): 6 capsules; 2 rods

- Levonorgestrel-releasing intrauterine system (LNG-IUS)

Comparison groups included no hormonal method or a non-hormonal contraceptive, a different regimen of the same progestin-only contraceptive, another progestin-only contraceptive, and a contraceptive or supplement containing estrogen.

Studies were conducted in the USA, South America, Europe, Africa, and Asia; some were conducted on multiple continents. Duration of prospective follow up or retrospective data collection was six months to two years for 11 studies, while 5 studies lasted three years or more.

Three studies focused on adolescents and young women. Bonny 2009 analyzed data from a larger study of hormonal contraceptives and bone mineral density. Moore 1995 and Tuchman 2005 were retrospective chart reviews. 


\section{Risk of bias in included studies}

Three of the five RCTs did not have any information on randomization method or allocation concealment (WHO 1983; Ball 1991; Westhoff 2007). The other two RCTs reported the method of randomization and allocation concealment (Salem 1988; Sivin 1998). Two RCTs had information on blinding. Ball 1991 was reportedly "single-blind." For the trials used in Westhoff 2007, the evaluators were blinded.

Incomplete outcome data (attrition bias)—Of 16 studies, 5 had losses of $25 \%$ or more in at least one group. Three were prospective studies (RCTs or non-randomized). For Tankeyoon 1976, the COC group was reduced by $25 \%$. In Castle 1978, losses to follow up were 39\% (DMPA 150) versus 23\% (DMPA 450). Westhoff 2007 had study discontinuation rates of 75\% (DMPA-SC 104) and 79\% (DMPA-IM 150). The retrospective studies generally had complete outcome data due to the inclusion criteria for cases. However, two of the six were missing substantial data from the later years. For Espey 2000 at two years, weight measures were not available for $70 \%$ of interval group and $49 \%$ of the postpartum group. In Sule 2005, the sample was reduced to $54 \%$ at three years.

Selective reporting (reporting bias)_After randomization, Taneepanichskul 1998 excluded women who developed a chronic disease or disorder during method use. This may have biased the results. Weight gain is associated with development of some diseases and disorders.

Other potential sources of bias-Potential confounding was addressed in four nonrandomized studies. Two studies considered confounding in the design (Pantoja 2010; Dal'Ava 2012). Both matched on age and baseline BMI. Two other studies conducted analysis that adjusted for potential confounders (Moore 1995; Bonny 2009). However, at least one of the comparison groups did not meet our inclusion criteria in these analyses. Therefore, we did not include the results of those analyses in this review. Details are in Characteristics of included studies.

\section{Effects of interventions}

Results are grouped according to four types of progestin-only contraceptives studied. One trial examined progestin-only pills, 10 studies addressed DMPA, one investigated the LNGIUS and four examined Norplant (one of which also included DMPA). We have subdivided the sections into studies comparing POCs with combination contraceptives, with no hormonal contraceptive, and with other POCs.

Progestin-only oral contraceptives-In the RCT of Ball 1991, weight change at six months was similar for the norethisterone $350 \mu \mathrm{g}$ and the levonorgestrel $30 \mu \mathrm{g}$ groups. Mean changes were small.

\section{Depot medroxyprogesterone acetate}

POC versus a combination contraceptive: Depot medroxyprogesterone acetate $150 \mathrm{mg} /$ $\mathrm{mL}$ (DMPA) was compared to a contraceptive or supplement that also contained estrogen in three studies. Bonny 2009 compared mean percentage changes in total body fat and lean body mass at six months for DMPA 150 plus placebo injection versus DMPA plus estradiol cypionate $5 \mathrm{mg}\left(\mathrm{E}_{2} \mathrm{C}\right)$. The study targeted adolescents, ages 12 to 18 years. The DMPA group was not significantly different from the DMPA plus $\mathrm{E}_{2} \mathrm{C}$ group for mean change in total body fat (\%) and in lean body mass (\%). However, when compared to a group using no hormonal method, the DMPA group had a greater change in total body fat (\%) (MD 11.00; 95\% CI 2.64 to 19.36) (Analysis 3.1) and a greater change in lean body mass (\%) (MD 
$-4.00 ; 95 \%$ CI -6.93 to -1.07 ) (Analysis 3.2). The retrospective study of Tuchman 2005 focused on adolescents and young women, ages 12 to 21 years. At 6 and 12 months, the DMPA group was similar to the group using medroxyprogesterone acetate (MPA) plus $\mathrm{E}_{2} \mathrm{C}$ and to the COC users for mean weight change and mean percentage weight change (Tuchman 2005). In the small study of Tankeyoon 1976, the DMPA and COC groups were not significantly different in the proportions that gained at least $1 \mathrm{~kg}$ by months 6 and 12 .

POC versus another POC: DMPA $150 \mathrm{mg} / \mathrm{mL}$ was compared with other DMPA formulations or regimens in three studies. In Castle 1978, the mean changes in weight at six months were small and similar for the DMPA 150 and DMPA 450 groups. The retrospective study of Espey 2000 did not show a significant difference in weight gain at one or two years for those who initiated DMPA at 20 weeks or more after pregnancy (interval group) versus initiation at 5 to 8 weeks after pregnancy (postpartum group). In the RCT analyzed in Westhoff 2007, weight change was comparable for the DMPA 150 group and the group with subcutaneous DMPA 104.

Two studies examined DMPA $150 \mathrm{mg} / \mathrm{mL}$ versus NET-EN $200 \mathrm{mg}$. In WHO 1983, mean weight changes at 12 and 24 months did not differ significantly for the DMPA group versus the group administered NET-EN at 60-day intervals. Weight change was also similar for two NET-EN regimens of 60 day-intervals versus 84-day intervals. For the RCT of Salem 1988, the units for weight were not reported (lbs or $\mathrm{kg}$ ). However, mean changes in weight at one year were similar for the DMPA and the NET-EN groups.

POC versus no hormonal contraceptive: DMPA $150 \mathrm{mg} / \mathrm{mL}$ was compared to a nonhormonal IUD in two retrospective studies. Taneepanichskul 1998 did not show a difference between the DMPA and IUD groups at 120 months. For Pantoja 2010, mean weight gain $(\mathrm{kg})$ was greater for the DMPA group versus the IUD group at one, two, and three years: mean difference 2.28 (Analysis 11.2), 2.71 (Analysis 11.3), and 3.17 (Analysis 11.4), respectively. For each year, the difference between contraceptive groups was notable within the normal to lower weight group (BMI < 25) and within the overweight group (BMI 25 to 29.9), but not within the obese group (BMI $>=30$ ).

Levonorgestrel-releasing intrauterine system (LNG-IUS)-In Dal'Ava 2012, the LNG-IUS was compared to a non-hormonal IUD with the Wilcoxon paired test (Analysis 17.1). At 12 months, the LNG-IUS group reportedly differed in the percent change in body fat mass compared to the non-hormonal IUD group (2.5\% versus $-1.3 \%$, respectively; reported $\mathrm{P}$ value $=0.029$ ). The LNG-IUS group also reportedly differed from the nonhormonal IUD users in percent change in lean body mass $(-1.4 \%$ versus $1.0 \%$, respectively; reported $\mathrm{P}$ value $=0.027)$. However, these groups reportedly did not differ significantly for changes in weight or the central-peripheral fat ratio.

Implants-An implant with six capsules (Norplant) was compared to other hormonal contraceptives and to no hormonal contraceptive use. For the retrospective study of Sule 2005 , the Norplant group had a significantly greater weight increase $(\mathrm{kg})$ than the nonhormonal IUD group at one year (mean difference 1.10; 95\% CI 0.36 to 1.84) (Analysis 13.2), but not at three years. The Norplant group was not significantly in weight change from that of the COC group. The retrospective study of Moore 1995 targeted adolescents and young women, ages 15 to 30 years. The Norplant and DMPA groups were not significantly different in mean weight change at one year. Salem 1984 showed a greater weight change $(\mathrm{kg})$ at six months for the Norplant group versus the non-hormonal IUD group (MD 0.47; 95\% CI 0.29 to 0.65) (Analysis 13.1). The Norplant group also had a greater weight change $(\mathrm{kg})$ than the group that used barrier, 'local', or no contraceptive method (mean difference $0.74 ; 95 \%$ CI 0.52 to 0.96 ) (Analysis 14.1 ). In the RCT of Sivin 
1998, mean weight change was not significantly different for the Norplant group versus the two-rod implant group at one, three, and five years.

\section{Discussion}

\section{Sensitivity analysis}

Study results were summarized in Table 1. For the planned sensitivity analysis, we removed retrospective studies as well as studies with high losses to follow up or to method discontinuation (i.e., 25\% or greater) (Table 2). Three studies showed differences in weight gain or body composition between the progestin-only group and a comparison group; two studies lasted six months and one was 12 months. Bonny 2009 was a small study of adolescents from a larger trial. The DMPA group had a greater increase in body fat percentage, and a greater decrease in lean body mass, compared to the group using no hormonal contraceptive. Within Dal'Ava 2012, participants using the LNG-IUS reportedly had an increase in fat mass and decrease in lean mass compared to the non-hormonal IUD users. However, the groups did not differ significantly for weight change. In Salem 1984, implant users showed a greater weight gain than the IUD users and the group that used barrier, 'local', or no contraceptive method.

\section{Summary of main results}

We were not able to conduct meta-analysis due to the range of contraceptive methods examined and different reporting for weight change. Five of the 16 studies showed or reported significant differences between groups in weight change or body composition change (Salem 1984; Sule 2005; Bonny 2009; Pantoja 2010; Dal'Ava 2012). Two of the five studies examined DMPA, two focused on Norplant (six capsules) and one examined the LNG-IUS. The differences were noted in the comparisons with groups using no hormonal contraceptives. Of these five studies, three remained in the sensitivity analysis. Bonny 2009 examined DMPA, focused on adolescents, and appropriately measured change in body fat $(\%)$ and lean body mass (\%) rather than weight change alone. The DMPA group differed from the group using no hormonal contraceptive at six months. Salem 1984 assessed Norplant and provided mean weight change (kg) at six months. The Norplant group differed from the IUD group and from a group using other non-hormonal or no contraceptive method. In Dal' Ava 2012, the LNG-IUS group differed from the non-hormonal IUD group in fat mass and lean mass changes at 12 months.

Actual mean weight gain was limited at 6 or 12 months (Table 1), i.e., less than $2 \mathrm{~kg}$ for most studies. The five studies with multi-year data showed that mean weight change was approximately twice as much at two or three years than at one year, but was generally similar for both study groups. Seven studies had data from two or more years of contraceptive use:

- Three RCTs compared two POCs (WHO 1983; Sivin 1998; Westhoff 2007). The DMPA or implant groups gained similar amounts of weight over one to three years.

- Three retrospective studies compared a POC to a non-hormonal IUD (Taneepanichskul 1998; Sule 2005; Pantoja 2010). Only Pantoja 2010 showed more weight gain for the DMPA group at one, two, and three years, but interestingly not within the obese group (BMI > $=30$ ).

- The retrospective study of Espey 2000 showed two DMPA groups to be similar in weight gain at one and two years. 


\section{Overall completeness and applicability of evidence}

Of the 16 studies, 12 had data from a year or more of contraceptive use, of which 7 had data from two years or more. Weight gain (or the perception of weight gain) is frequently cited as a reason for discontinuing a contraceptive method. If a method is associated with weight gain, a year is long enough to detect some change, though the amount may not be significant. Of the seven studies with data from two years or more of contraceptive use, most showed the study groups to be similar for weight gain, regardless of whether the comparison group used POCs, combination contraceptives, or no hormonal methods.

Studies of progestin-only contraceptives and weight change were limited in type and number. Only one study of progestin-only pills was found that met our inclusion criteria. For implants, we found the most weight change data for Norplant (with six capsules). However, Norplant is no longer marketed, while single-rod and two-rod implants are currently available. However, most studies of currently marketed implants did not meet our inclusion criteria, mainly due to the lack of comparative weight change data. The one exception was a study in which Norplant was compared to a two-rod implant. Consequently, we do not have much evidence regarding weight change with currently marketed implants. Further, we did not find any studies of hormonal IUDs that met our inclusion criteria.

\section{Quality of the evidence}

After conducting the review, we assessed the quality of evidence as noted earlier (Assessment of risk of bias in included studies). The results are shown by contraceptive method of focus and evidence quality (Table 3 ). We consider the overall quality of evidence to be moderate to low, given that evidence from the 16 studies was evenly divided across the categories (high, moderate, low, or very low quality). The high- or moderate-quality evidence came from the following: a study of progestin-only pills that showed no significant difference in weight change; four of 10 DMPA studies, one of which showed adolescents using DMPA had increased body fat and decreased lean body mass; two of four implant studies with one showing a greater weight increase for Norplant users; and the intrauterine system study that reported the LNG-IUS users had an increase in total fat mass and decrease in lean body mass.

Sample sizes varied. Three studies had 32 to 51 participants, and were unlikely to have had sufficient power to detect differences in weight gain. One study had 76 participants. Seven studies had 100 to 400 participants, and five ranged from 534 to 3172 . A few had comparison groups that were not used in this review, because the group did not meet our inclusion criteria.

Most studies did not adjust for potential confounding factors of weight change. Some had adjusted analyses that we did not use since a comparison group did not meet our inclusion criteria.

\section{Potential biases in the review process}

We selected studies that had data on mean weight change, mean change in body composition, or proportion that gained or lost a specified amount of weight. Several studies were excluded due to not reporting the data we needed. Many studies were older, which limited our ability to obtain additional information from the researchers.

\section{Agreements and disagreements with other studies or reviews}

Many of the concerns about weight gain with POC use are based on perceptions and discontinuation reasons rather than measures of actual weight change (Paul 1997; Bonny 2004; Berenson 2008). We found limited evidence of significant change for POC users 
versus those who did not use hormonal contraceptives. Actual weight gain was relatively low up to one year. Similarly, a Cochrane review showed no clear evidence of weight gain with the use of combined hormonal contraceptives (Gallo 2011). People may gain weight over time, regardless of contraceptive use.

However, DMPA may be a concern for adolescents who are already obese (Curtis 2009). One study that focused on adolescents (Bonny 2009) showed an increase in total body fat and a decrease in lean body mass for the DMPA group versus those with no hormonal contraceptive use. Two retrospective studies included adolescents (Moore 1995 (15 to 30 years old); Tuchman 2005 (12 to 21 years old). However, they did not show a significant difference between groups or much weight gain within groups.

\section{Authors' conclusions}

\section{Implications for practice}

We found limited evidence of weight gain when using progestin-only contraceptives. Some differences were noted when a POC was compared to no hormonal contraceptive. Actual mean weight gain was low for 6 to 12 months, i.e., less than $2 \mathrm{~kg}$ for most studies. More weight gain was noted at two and three years, but was generally similar for the study groups. People may gain weight over time regardless of contraceptive use. Appropriate and accurate counseling about typical weight gain may help reduce discontinuation of contraceptives due to perceptions of weight gain.

\section{Implications for research}

The five RCTs each compared similar progestin-only contraceptives, which might account for the groups being similar for weight change. Five non-randomized studies showed some differences for POCs versus no hormonal contraceptives (three prospective and two retrospective). Weight change is rarely the focus of prospective contraception studies. Welldesigned RCTs assessing weight change over time would better address this issue. However, careful counseling and follow up are needed to avoid the high rates for losses to follow up and discontinuation found in many contraceptive studies.

\section{Summary of findings tables}

\section{Additional tables}

\section{Acknowledgments}

Sources of support

Internal sources

- $\quad$ No sources of support provided

External sources

- $\quad$ National Institute of Child Health and Human Development, USA

For conducting the review; FHI 360 (LL, MC, CO)

- $\quad$ US Agency for International Development, USA

For conducting the review; FHI 360 (LL, MC, CO)

- National Institute of Child Health and Human Development, USA

Grant for Infrastructure for Population Research at Princeton University; Grant R24HD047879 (JT; for working on the review) 


\section{References to studies}

\section{Included studies}

Ball 1991. Ball MJ, Ashwell E, Gillmer MD. Progestagen-only oral contraceptives: comparison of the metabolic effects of levonorgestrel and norethisterone. Contraception. 1991; 44(3):223-33. [PubMed: 1764941]

Bonny 2009. Bonny AE, Secic M, Cromer BA. A longitudinal comparison of body composition changes in adolescent girls receiving hormonal contraception. Journal of Adolescent Health. 2009; 45(4):423-5. [PubMed: 19766950]

Castle 1978. Castle WM, Sapire KE, Howard KA. Efficacy and acceptability of injectable medroxyprogesterone: a comparison of 3-monthly and 6-monthly regimens. South African Medical Journal. 1978; 53(21):842-5. [PubMed: 694638]

Dal'Ava 2012. Dal'Ava N, Bahamondes L, Bahamondes MV, de Oliveira Santos A, Monteiro I. Body weight and composition in users of levonorgestrel-releasing intrauterine system. Contraception. 2012; 86(4):350-3. [PubMed: 22445431]

Espey 2000. Espey E, Steinhart J, Ogburn T, Qualls C. Depo-provera associated with weight gain in Navajo women. Contraception. 2000; 62(2):55-8. [PubMed: 11102587]

Moore 1995. Moore LL, Valuck R, McDougall C, Fink W. A comparative study of one-year weight gain among users of medroxyprogesterone acetate, levonorgestrel implants, and oral contraceptives. Contraception. 1995; 52(4):215-9. [PubMed: 8605778]

Pantoja M, Medeiros T, Baccarin MC, Morais S, Fernandes AM. Variation of weight among users of the contraceptive with depot-medroxyprogesterone acetate according to body mass index in a sixyear follow-up. Revista Brasileira de Ginecologia e Obstetricia. 2009; 31(8):380-4. [PubMed: 19838585]

Pantoja 2010. Pantoja M, Medeiros T, Baccarin MC, Morais SS, Bahamondes L, Fernandes AM. Variations in body mass index of users of depot-medroxyprogesterone acetate as a contraceptive. Contraception. 2010; 81(2):107-11. [PubMed: 20103446]

Salem 1984. Salem, HT.; Abdullah, KA.; Shaaban, MM. Norplant and lactation. In: Shaaban, MM., editor. The Norplant subdermal contraceptive system; Proceedings of the Symposium on Longterm Subdermal Contraceptive Implants; 1984 February 23-24; Assuit, Egypt: Assiut University; 1984. p. 139-49.

Salem 1988. Salem HT, Salah M, Aly MY, Thabet AI, Shaaban MM, Fathalla MF. Acceptability of injectable contraceptives in Assiut, Egypt. Contraception. 1988; 38(6):697-710. [PubMed: 2975583]

Sivin I, Campodonico I, Kiriwat O, Holma P, Diaz S, Wan L, et al. The performance of levonorgestrel rod and Norplant contraceptive implants: a 5 year randomized study. Human Reproduction. 1998; 13(12):3371-8. [PubMed: 9886517]

Sivin 1998. Sivin I, Viegas O, Campodonico I, Diaz S, Pavez M, Wan L, et al. Clinical performance of a new two-rod levonorgestrel contraceptive implant: a three-year randomized study with Norplant implants as controls. Contraception. 1997; 55(2):73-80. [PubMed: 9071515]

Sule 2005. Sule S, Shittu O. Weight changes in clients on hormonal contraceptives in Saria, Nigeria. African Journal of Reproductive Health. 2005; 9(2):92-100. [PubMed: 16485589]

Taneepanichskul S, Reinprayoon D, Jaisamrarn U. Effects of DMPA on weight and blood pressure in long term acceptors. Contraception. 1999; 59(5):301-3. [PubMed: 10494483]

Taneepanichskul 1998. Taneepanichskul S, Reinprayoon D, Khaosaad P. Comparative study of weight change between long-term DMPA and IUD acceptors. Contraception. 1998; 58(3):149-51.

Tankeyoon 1976. Tankeyoon M, Dusitsin N, Poshyachinda V, Larsson-Cohn U. A study of glucose tolerance, serum transaminase and lipids in women using depot-medroxyprogesterone acetate and a combination-type oral contraceptive. Contraception. 1976; 14(2):199-214. [PubMed: 949896]

Tuchman 2005. Tuchman LK, Huppert JS, Huang B, Slap GB. Adolescent use of the monthly contraceptive injection. Journal of Pediatric and Adolescent Gynecology. 2005; 18(4):255-60. [PubMed: 16171729] 
Jain J, Jakimiuk AJ, Bode FR, Ross D, Kaunitz AM. Contraceptive efficacy and safety of DMPA-SC. Contraception. 2004; 70(4):269-75. [PubMed: 15451329]

Westhoff 2007. Westhoff C, Jain JK, Milsom I, Ray A. Changes in weight with depot medroxyprogesterone acetate subcutaneous injection $104 \mathrm{mg} / 0.65 \mathrm{~mL}$. Contraception. 2007; 75(4):261-7. [PubMed: 17362703]

World Health Organization. Multinational comparative clinical trial of long-acting injectable contraceptives: norethisterone enanthate given in two dosage regimens and depotmedroxyprogesterone acetate. A preliminary report. Contraception. 1982; 25(1):1-11. [PubMed: 6460593]

WHO 1983. World Health Organization. Multinational comparative clinical trial of long-acting injectable contraceptives: norethisterone enanthate given in two dosage regimens and depotmedroxyprogesterone acetate. Final report Contraception. 1983; 28(1):1-20.

\section{Excluded studies}

Agoestina 1978. Agoestina, T.; Biben, A. Report on file. 1978. Use of Depo Provera in immediate post partum and lactating period at Dr Hasan Sadikin Hospital.

Bahamondes 2010. Bahamondes MV, Monteiro I, Castro S, Espejo-Arce X, Bahamondes L. Prospective study of the forearm bone mineral density of long-term users of the levonorgestrelreleasing intrauterine system. Human Reproduction. 2010; 25(5):1158-64. [PubMed: 20185512]

Barsivala 1974. Barsivala V, Virkar K, Kulkarni RD. Thyroid functions of women taking oral contraceptives. Contraception. 1974; 9(3):305-14. [PubMed: 4442279]

Beksinska 2010. Beksinska ME, Smit JA, Kleinschmidt I, Milford C, Farley TM. Prospective study of weight change in new adolescent users of DMPA, NET-EN, COCs, nonusers and discontinuers of hormonal contraception. Contraception. 2010; 81(1):30-4. [PubMed: 20004270]

Berenson 1997. Berenson AB, Wiemann CM, Rickerr VI, McCombs SL. Contraceptive outcomes among adolescents prescribed Norplant implants versus oral contraceptives after one year of use. American Journal of Obstetrics and Gynecology. 1997; 176(3):586-92. [PubMed: 9077611]

*. Berenson AB, Rahman M. Changes in weight, total fat, percent body fat, and central-to-peripheral fat ratio associated with injectable and oral contraceptive use. American Journal of Obstetrics and Gynecology. 2009; 200(3):329, e1-8. [PubMed: 19254592]

Berenson 2009. Rahman M, Berenson AB. Self-perception of weight gain among multiethnic reproductive-age women. Journal of women's health (2002). 2012; 21(3):340-6.

Bonny A, Camlin K, Harvey R, Islam KM, Debanne S. Prospective analysis of weight changes in adolescent females initiating depot medroxyprogesterone acetate (DMPA), oral contraceptive pills (OC), or no hormonal contraceptive method. Journal of Adolescent Health. 2003; 32(2):134.

Bonny AE, Secic M, Cromer BA. Relationship between weight and bone mineral density in adolescents on hormonal contraception. Journal of pediatric and adolescent gynecology. 2011; 24(1):35-8. [PubMed: 20709582]

Bonny 2006. Bonny AE, Ziegler J, Harvey R, Debanne SM, Secic M, Cromer BA. Weight gain in obese and nonobese adolescent girls initiating depot medroxyprogesterone, oral contraceptive pills, or no hormonal contraceptive method. Archives of Pediatrics \& Adolescent Medicine. 2006; 160(1):40-5. [PubMed: 16389209]

Chen 2011. Chen J, Wang XJ, Liang Y, Jin Q. Clinic observation of a levonorgestrel-releasing intrauterine system inserted immediately after artificial abortion. Zhonghua yi xue za zhi. 2011; 91(45):3176-8. Published data only (unpublished sought but not used). [PubMed: 22333097]

Clark MK, Dillon JS, Sowers M, Nichols S. Weight, fat mass, and central distribution of fat increase when women use depot-medroxyprogesterone acetate for contraception. International Journal of Obesity. 2005; 29(10):1252-8. [PubMed: 15997247]

Clark 2005. Clark MK, Sowers MR, Nichols S, Levy B. Bone mineral density changes over two years in first-time users of depot medroxyprogesterone acetate. Fertility and Sterility. 2004; 82(6): 1580-6. [PubMed: 15589863]

Costa 2012. Costa ML, Cecatti JG, Krupa FG, Rehder PM, Sousa MH, Costa-Paiva L. Progestin-only contraception prevents bone loss in postpartum breastfeeding women. Contraception. 2012; 85(4):374-80. [PubMed: 22036473] 
Dahlberg 1982. Dahlberg K. Some effects of depo-medroxyprogesterone acetate (DMPA): observations in the nursing infant and in the long-term user. International Journal of Gynaecology and Obstetrics. 1982; 20(1):43-8. [PubMed: 6126406]

El Mahgoub 1980. El Mahgoub S. Body weight and cycle control of injectable contraceptives. Journal of Reproductive Medicine. 1980; 24(3):119-26. [PubMed: 7373592]

Hall 1980. Hall WD, Douglas MB, Blumenstein BA, Hatcher RA. Blood pressure and oral progestational agents. A prospective study of 119 black women. American Journal of Obstetrics and Gynecology. 1980; 136(3):344-8. [PubMed: 7352524]

Havranek 1972. Havranek F, Tichy M, Divila F, Hejda V. Experience with the contraceptive effect of Depo-Provera, 300mg and 450mg administered at 6 month intervals [Zkusenosti s antikoncepcni ucinnosti Depo-Provery v davce 300mg a 450mg podanych v intervalech 6 mesicu]. Ceskoslovenska Gynekologie. 1972; 37(2):95-6. [PubMed: 5023983]

Kaunitz 2009. Kaunitz AM, Darney PD, Ross D, Wolter KD, Speroff L. Subcutaneous DMPA vs. intramuscular DMPA: a 2-year randomized study of contraceptive efficacy and bone mineral density. Contraception. 2009; 80(1):7-17. [PubMed: 19501210]

Mangan 2002. Mangan SA, Larsen PG, Hudson S. Overweight teens at increased risk for weight gain while using depot medroxyprogesterone acetate. Journal of Pediatric and Adolescent Gynecology. 2002; 15(2):79-82. [PubMed: 12057528]

Olsson 1988. Olsson SE, Odlind V, Johansson ED, Sivin I. Contraception with NORPLANT implants and NORPLANT-2 implants (two covered rods). Results from a comparative clinical study in Sweden. Contraception. 1988; 37(1):61-73. [PubMed: 3130221]

Ortayli 2001. Ortayli N, Bulut A, Sahin T, Sivin I. Immediate postabortal contraception with the levonorgestrel intrauterine device, Norplant, and traditional methods. Contraception. 2001; 63(6): 309-14. [PubMed: 11672552]

Risser 1999. Risser WL, Gefter LR, Barratt MS, Risser JM. Weight change in adolescents who used hormonal contraception. Journal of Adolescent Health. 1999; 24(6):433-6. [PubMed: 10401972]

Segall-Gutierrez 2012. Segall-Gutierrez P, Xiang AH, Watanabe RM, Trigo E, Stanczyk FZ, Liu X, et al. Deterioration in cardiometabolic risk markers in obese women during depot medroxyprogesterone acetate use. Contraception. 2012; 85(1):36-41. [PubMed: 22067800]

WHO 1978. World Health Organization. Multinational comparative clinical evaluation of two longacting injectable contraceptive steroids: noresthisterone oenanthate and medroxyprogesterone acetate. 2. Bleeding patterns and side effects. Contraception. 1978; 17(5):395-406. [PubMed: 657807]

Yela 2006. Yela DA, Monteiro IM, Bahamondes LG, Castillo SD, Bahamondes MV. Weight variation in users of the levonorgestrel-releasing intrauterine system, of the copper IUD and of medroxyprogesterone acetate in Brazil. Revista da Associacao Medica Brasileira. 2006; 52(1): 32-6. [PubMed: 16622536]

Zheng 1999. Zheng SR, Zheng HM, Qian SZ, Sang GW, Kaper RF. A randomized multicenter study comparing the efficacy and bleeding pattern of a single-rod (Implanon) and a six-capsule (Norplant) hormonal contraceptive implant. Contraception. 1999; 60(1):1-8. [PubMed: 10549446]

\section{Studies awaiting classification}

*. Madden, TE. [accessed 07 Feb 2013] Weight Change Among Users of Three Progestin-Only Methods of Contraception over a 12-Month Time Period (BMI). http://clinicaltrials.gov/show/ NCT01592058Other: NCT01592058

Madden 2013. Vickery Z, Madden T, Zhao Q, Secura GM, Allsworth JE, Peipert JF. Weight change at 12 months in users of three progestin-only contraceptive methods. Contraception. 2013 Mar 18. Epub ahead of print. Published data only (unpublished sought but not used).

\section{Ongoing studies}

Bonny 2012. Bonny, A. [accessed 21 Feb 2013] Drug Exposure and Depot Medroxyprogesterone Acetate (DMPA) in Adolescent Subjects. http://clinicaltrials.gov/ct2/show/NCT01461824 
Madden 2012b. Madden, TE. [accessed 21 Feb 2013] Comparison of Body Composition \& Weight Change in Users of Progestin-only Contraception During the First Year of Use (DEXA). http:// clinicaltrials.gov/ct2/show/NCT01579773

\section{Other references}

\section{Additional references}

ACOG 2006. American College of Obstetricians and Gynecologists. Use of hormonal contraception in women with coexisting medical conditions. Washington, D.C: American College of Obstetricians and Gynecologists; 2006. ACOG technical bulletin.

Amatayakul 1980. Amatayakul K, Sivasomboon B, Thanangkul O. A study of the mechanism of weight gain in medroxyprogesterone acetate users. Contraception. 1980; 22(6):605-22. [PubMed: 7214909]

Bartz 2011. Bartz, D.; Goldberg, AB. Injectable contraceptives. In: Hatcher, RA.; Trussell, J.; Nelson, AL.; Cates, W.; Kowal, D.; Policar, MS., editors. Contraceptive Technology. 20. New York: Ardent Media, Inc; 2011. p. 209-36.revised

Berenson 2008. Berenson AB, Odom SD, Breitkopf CR, Rahman M. Physiologic and psychologic symptoms associated with use of injectable contraception and $20 \mu \mathrm{g}$ oral contraceptive pills. American Journal of Obstetrics and Gynecology. 2008; 199(4):351, e1-12. [PubMed: 18599013]

Bonny 2004. Bonny AE, Britto MT, Huang B, Succop P, Slap GB. Weight gain, adiposity, and eating behaviors among adolescent females on depot medroxyprogesterone acetate (DMPA). Journal of Pediatric and Adolescent Gynecology. 2004; 17(2):109-15. [PubMed: 15050987]

CDC 2012. Centers for Disease Control and Prevention. [accessed 19 Dec 2012] Defining Overweight and Obesity. http://www.cdc.gov/obesity/adult/defining.html

Chin 2009. Chin JR, Swamy GK, Ostbye T, Bastian LA. Contraceptive use by obese women 1 year postpartum. Contraception. 2009; 80(5):463-8. [PubMed: 19835721]

Curtis 2009. Curtis KM, Ravi A, Gaffield ML. Progestogen-only contraceptive use in obese women. Contraception. 2009; 80(4):346-54. [PubMed: 19751857]

Edelman 2009. Edelman AB. Contraceptive considerations in obese women. Contraception. 2009; 80(6):583-90. [PubMed: 19913155]

Faculty of Family Planning 2003. Faculty of Family Planning and Reproductive Health Care Clinical Effectiveness Unit. New product review (April 2003) desogestrel-only pill (Cerazette). Journal of Family Planning and Reproductive Health Care. 2003; 29(3):162-4. [PubMed: 12885316]

Flegal 2000. Flegal KM, Troiano RP. Changes in the distribution of body mass index of adults and children in the US population. International Journal of Obesity and Related Metabolic Disorders. 2000; 24(7):807-18. [PubMed: 10918526]

Flegal 2012. Flegal KM, Carroll MD, Kit BK, Ogden CL. Prevalence of obesity and trends in the distribution of body mass index among US adults, 1999-2010. JAMA. 2012; 307(5):491-7. [PubMed: 22253363]

FWHC 2010. Feminist Women's Health Center. [accessed 15 Jun 2010] Mini-pills (progesterone-only oral contraceptives). http://www.fwhc.org/birth-control/minipill.htm

Gallo 2011. Gallo MF, Lopez LM, Grimes DA, Schulz KF, Helmerhorst FM. Combination contraceptives: effects on weight. Cochrane Database of Systematic Reviews. 2011; (9):Art. No.: CD003987.10.1002/14651858.CD003987.pub4

Grimes 2005. Grimes DA, Shields WC. Family planning for obese women: challenges and opportunities. Contraception. 2005; 72(1):1-4. [PubMed: 15964284]

Grimes 2007. Grimes DA, Lopez LM, Manion C, Schulz KF. Cochrane systematic reviews of IUD trials: lessons learned. Contraception. 2007; 75(6 Suppl):S55-9. [PubMed: 17531618]

Grimes 2010. Grimes DA, Lopez LM, O’Brien PA, Raymond EG. Progestin-only pills for contraception. Cochrane Database of Systematic Reviews. 2010; (1):Art. No.: CD007541.10.1002/14651858.CD007541 
Higgins 2011. Higgins, JPT.; Green, S., editors. Cochrane Handbook for Systematic Reviews of Interventions 5.1.0 [updated March 2011]. The Cochrane Collaboration; 2011. Available from www.cochrane-handbook.org [accessed 24 October 2012]

Lopez 2012. Lopez LM, Grimes DA, Schulz KF. Steroidal contraceptives: effect on carbohydrate metabolism in women without diabetes mellitus. Cochrane Database of Systematic Reviews. 2012; (4):Art. No.: CD006133.10.1002/14651858.CD006133.pub4

Lopez 2013. Lopez LM, Grimes DA, Chen-Mok M, Westhoff C, Edelman A, Helmerhorst FM. Hormonal contraceptives for contraception in overweight or obese women. Cochrane Database of Systematic Reviews. 2013; (4):Art. No.: CD008452.10.1002/14651858.CD008452.pub3

Najjar 1987. Najjar MF, Rowland M. Anthropometric reference data and prevalence of overweight, United States, 1976-80. Vital Health Stat 11. 1987; 238:1-73. [PubMed: 3424692]

Ogden 2007. Ogden, CL.; Carroll, MD.; McDowell, MA.; Flegal, KM. NCHS data brief no 1. Hyattsville (MD): National Center for Health Statistics; 2007. Obesity among adults in the United States - no change since 2003-2004.

Paul 1997. Paul C, Skegg DC, Williams S. Depot medroxyprogesterone acetate. Patterns of use and reasons for discontinuation. Contraception. 1997; 56(4):209-14. [PubMed: 9408701]

Pelkman 2001. Pelkman CL, Chow M, Heinback RA, Rolls BJ. Short-term effects of a progestional contraceptive drug on food intake, resting energy expenditure, and body weight in young women. American Journal of Clinical Nutrition. 2001; 73(1):19-26. [PubMed: 11124744]

Prentice 2006. Prentice AM. The emerging epidemic of obesity in developing countries. International Journal of Epidemiology. 2006; 35(1):93-9. [PubMed: 16326822]

Raymond 2011. Raymond, EG. Progestin-only pills. In: Hatcher, RA.; Trussell, J.; Nelson, AL.; Cates, W., Jr; Kowal, D.; Policar, MS., editors. Contraceptive technology. 20. New York: Ardent Media, Inc; 2011. p. 237-47.

Schraudenbach 2009. Schraudenbach A, McFall S. Contraceptive use and contraception type in women by body mass index category. Womens Health Issues. 2009; 19(6):381-9. [PubMed: 19879452]

Schulz 2002. Schulz KF, Grimes DA. Allocation concealment in randomised trials: defending against deciphering. Lancet. 2002; 359(9306):614-8. [PubMed: 11867132]

Sivin 2003. Sivin I. Risks and benefits, advantages and disadvantages of levonorgestrel-releasing contraceptive implants. Drug Safety. 2003; 26(5):303-35. [PubMed: 12650633]

Strauss 2005. Strauss, SE.; Richardson, WS.; Glasziou, P.; Haynes, RB. Evidence-based Medicine: How to Practice and Teach EBM. 3. New York: Churchill Livingstone; 2005.

Trussell 2009. Trussell J, Schwarz EB, Guthrie K. Obesity and oral contraceptive pill failure. Contraception. 2009; 79(5):334-8. [PubMed: 19341843]

UN 2011. United Nations, Department of Economic and Social Affairs. [accessed 21 Feb 2013] World Contraceptive Use. 2011. http://www.un.org/esa/population/publications/contraceptive2011/ contraceptive2011.htm

Von Elm 2007. Von Elm E, Altman DG, Egger M, Pocock SJ, Gøtzsche PC, Vandebroucke JP. for the STROBE Initiative. The Strengthening the Reporting of Observational Studies in Epidemiology (STROBE) Statement: Guidelines for reporting observational studies. Lancet. 2007; 370(9596): 1453-7. [PubMed: 18064739]

WebMD 2010. WebMD. [accessed 15 Jun 2010] Progestin-only hormonal methods (mini-pills, implants, and shots). http://www.webmd.com/sex/birth-control/progestin-only-hormonalmethods-mini-pills-shots

WHO 2010. World Health Organization. [accessed 16 Feb 2011] Medical Eligibility Criteria for Contraceptive Use. 4http://www.who.int/reproductivehealth/publications/family_planning/ 9789241563888/en/index.html

\section{Appendices}

\section{Searches 2013}

MEDLINE via PubMed (01 Jan 2010 to 05 Jun 2013) 
(contraceptive agents, female[Mesh] OR contraceptive devices, female[Mesh] OR contracept*) AND (progest* OR "progestin only" OR "progestin only" contracept* OR "progestin only pill" OR progestin* OR progesteron* OR progestational, hormones, synthetic OR progestogen* OR progesterone OR gestagen OR "progestogen only") AND (body weight changes OR weight gain OR weight loss OR body mass index OR BMI OR weight) NOT (cancer[ti] OR polycystic [ti] OR exercise [ti] OR physical activity[ti] OR postmenopaus*[ti])

limited to human, female

CENTRAL (2010 to 01 Jun 2013)

weight OR body mass index OR BMI in Abstract

AND contraception OR contraceptive in Title, Abstract or Keywords

NOT premenstrual OR dysmenor* OR endometr* OR *androgen* OR HIV OR polycystic OR

PCOS OR cancer OR exercise OR anorexia OR bulimic in Record Title

NOT postmenopausal OR post-menopausal OR hormone therapy OR male hormonal OR male contracept* OR testosterone in Record Title

POPLINE (2010 to 26 Dec 2012)

Global: weight OR BMI OR body mass index

Keyword: contraceptive agents, progestin OR Low-Dose Progestins

Filter: research report

LILACS (2010 to 26 Dec 2012)

contraceptive agents or Agentes Anticonceptivos Femeninos or Anticoncepcionais Femininos or contraceptive devices, female or Dispositivos Anticonceptivos Femeninos or Dispositivos Anticoncepcionais Femininos or contraceptives or Anticonceptivos or Anticoncepcionais [Words] AND weight or body weight or Peso Corporal or weight gain or Aumento de Peso or Ganho de Peso or weight reduction or weight loss or Pérdida de Peso or Perda de Peso or body weight changes or Cambios en el Peso Corporal or Alterações do Peso Corporal or body mass index or BMI [Words]

ClinicalTrials.gov (01 Jan 2010 to 26 Dec 2012)

Search terms: overweight OR obese OR obesity OR weight OR body mass index OR BMI

Condition: NOT (HIV OR polycystic OR PCOS OR cancer OR anorexia OR pulmonary OR metabolic OR amenorrhea)

Intervention: contraceptive OR contraception

Study type: interventional studies

Gender: studies with female participants

ICTRP (2010 to 26 Dec 2012)

1. Intervention: contraceptive $\mathrm{OR}$ contraception

2. Condition: contraceptive OR contraception Intervention: progestin OR progestinonly OR IUD OR implant OR medroxyprogesterone OR norethisterone 


\section{Searches 2010}

MEDLINE via PubMed (through 11 Jun 2010)

(contraceptive agents, female[Mesh] OR contraceptive devices, female[Mesh] OR contracept*) AND (progest* OR "progestin only" OR "progestin only" contracept* OR "progestin only pill" OR progestin* OR progesteron* OR progestational, hormones, synthetic OR progestogen* OR progesterone OR gestagen OR "progestogen only") AND (body weight changes OR weight gain OR weight loss OR body mass index OR BMI OR weight) NOT (cancer[ti] OR polycystic [ti] OR exercise [ti] OR physical activity[ti] OR postmenopaus*[ti])

limited to human, female

POPLINE (through 19 May 2010)

(progestin only contracept*/ contraceptive agents, progestin/low-dose progestins) \& (weight/ weight gain/weight loss/body weight/BMI/body mass index/ weight change)

CENTRAL (through 19 May 2010)

weight OR body mass index OR BMI in Abstract and contraception OR contraceptive in Title, Abstract or Keywords

NOT premenstrual OR dysmenor* OR endometr* OR *androgen* OR HIV OR polycystic OR

PCOS OR cancer OR exercise OR anorexia OR bulimic in Record Title

NOT postmenopausal OR post-menopausal OR hormone therapy OR male hormonal OR male contracept* OR testosterone in Record Title

EMBASE (through 15 Jun 2010)

(contraceptive agent, progestin --side effects

or

((contraceptive device or contraceptives or contracept*) and (gestagen! or progest? or progestin? or progesterone? or progestational, hormones, synthetic or progestogen? or progestin()only or progestin()only()contracept or progestin()only()pill or progestogen()only)))

and

(body weight! or weight gain or weight reduction or weight()loss or body()mass()index) not (cancer or polycystic or exercise or physical() activity or postmenopaus? or oral contraceptives, combined)

and body weight/de

limited to human

LILACS (through 01 Jul 2010)

contraceptive agents or Agentes Anticonceptivos Femeninos or Anticoncepcionais Femininos or contraceptive devices, female or Dispositivos Anticonceptivos Femeninos or 
Dispositivos Anticoncepcionais Femininos or contraceptives or Anticonceptivos or Anticoncepcionais [Words]

and weight or body weight or Peso Corporal or weight gain or Aumento de Peso or Ganho de Peso or weight reduction or weight loss or Pérdida de Peso or Perda de Peso or body weight changes or Cambios en el Peso Corporal or Alterações do Peso Corporal or body mass index or BMI [Words]

ClinicalTrials.gov (through 27 Apr 2010)

Search terms: overweight OR obese OR obesity OR weight OR body mass index OR BMI

Condition: NOT (HIV OR polycystic OR PCOS OR cancer OR anorexia OR pulmonary OR metabolic OR amenorrhea)

Intervention: contraceptive OR contraception

Study type: interventional studies

Gender: studies with female participants

ICTRP (through 07 Sep 2010)

1. Intervention: contraceptive $\mathrm{OR}$ contraception

2. Condition: contraceptive OR contraception Intervention: progestin OR progestinonly OR IUD OR implant OR medroxyprogesterone OR norethisterone

Data and analyses

1 Norethisterone $350 \mu \mathrm{g}$ versus levonorgestrel $30 \mu \mathrm{g}$

\begin{tabular}{|l|l|l|l|l|}
\hline Outcome or Subgroup & Studies & Participants & Statistical Method & Effect Estimate \\
\hline $\begin{array}{l}1.1 \text { Mean weight change (kg) at } 6 \\
\text { months }\end{array}$ & 1 & 39 & $\begin{array}{l}\text { Mean Difference (IV, Fixed, } \\
\text { 95\% CI) }\end{array}$ & $-0.60[-1.76,0.56]$ \\
\hline
\end{tabular}

\section{DMPA $150 \mathrm{mg} / \mathrm{mL}$ + placebo versus DMPA $150 \mathrm{mg} / \mathrm{mL}+\mathrm{E}_{2} \mathrm{C}$}

\begin{tabular}{|l|l|l|l|l|}
\hline Outcome or Subgroup & Studies & Participants & Statistical Method & Effect Estimate \\
\hline $\begin{array}{l}\text { 2.1 Mean change in total body fat } \\
(\%) \text { at } 6 \text { months }\end{array}$ & 1 & 15 & $\begin{array}{l}\text { Mean Difference (IV, } \\
\text { Fixed, 95\% CI) }\end{array}$ & $7.50[-0.47,15.47]$ \\
\hline $\begin{array}{l}\text { 2.2 Mean change in lean body mass } \\
(\%) \text { at } 6 \text { months }\end{array}$ & 1 & 15 & $\begin{array}{l}\text { Mean Difference (IV, } \\
\text { Fixed, 95\% CI) }\end{array}$ & $-2.20[-5.00,0.60]$ \\
\hline
\end{tabular}

\section{DMPA $150 \mathrm{mg} / \mathrm{mL}$ versus control (no hormonal method)}

\begin{tabular}{|l|l|l|l|l|}
\hline Outcome or Subgroup & Studies & Participants & Statistical Method & Effect Estimate \\
\hline $\begin{array}{l}\text { 3.1 Mean change in total body fat } \\
(\%) \text { at } 6 \text { months }\end{array}$ & 1 & 26 & $\begin{array}{l}\text { Mean Difference (IV, } \\
\text { Fixed, 95\% CI) }\end{array}$ & $11.00[2.64,19.36]$ \\
\hline $\begin{array}{l}3.2 \text { Mean change in lean body mass } \\
(\%) \text { at 6 months }\end{array}$ & 1 & 26 & $\begin{array}{l}\text { Mean Difference (IV, } \\
\text { Fixed, 95\% CI) }\end{array}$ & $-4.00[-6.93,-1.07]$ \\
\hline
\end{tabular}




\section{DMPA $150 \mathrm{mg} / \mathrm{mL}$ versus MPA + $E_{2} C$}

\begin{tabular}{|l|l|l|l|l|}
\hline Outcome or Subgroup & Studies & Participants & Statistical Method & Effect Estimate \\
\hline $\begin{array}{l}4.1 \text { Mean weight change (kg) at } 6 \\
\text { months }\end{array}$ & 1 & 70 & $\begin{array}{l}\text { Mean Difference (IV, Fixed, } \\
95 \% \text { CI) }\end{array}$ & -0.60 [-3.05, 1.85] \\
\hline $\begin{array}{l}4.2 \text { Mean weight change (kg) at } 12 \\
\text { months }\end{array}$ & 1 & 46 & $\begin{array}{l}\text { Mean Difference (IV, Fixed, } \\
95 \% \text { CI) }\end{array}$ & $-1.30[-6.37,3.77]$ \\
\hline $\begin{array}{l}4.3 \text { Mean percentage weight change } \\
\text { at } 6 \text { months }\end{array}$ & 1 & 70 & $\begin{array}{l}\text { Mean Difference (IV, Fixed, } \\
95 \% \text { CI) }\end{array}$ & $-0.60[-4.04,2.84]$ \\
\hline $\begin{array}{l}4.4 \text { Mean percentage weight change } \\
\text { at } 12 \text { months }\end{array}$ & 1 & 46 & $\begin{array}{l}\text { Mean Difference (IV, Fixed, } \\
95 \% \text { CI) }\end{array}$ & $-0.70[-7.58,6.18]$ \\
\hline
\end{tabular}

\section{DMPA $150 \mathrm{mg} / \mathrm{mL}$ versus COC}

\begin{tabular}{|c|c|c|c|c|}
\hline Outcome or Subgroup & Studies & Participants & Statistical Method & Effect Estimate \\
\hline $\begin{array}{l}5.1 \text { Mean weight change }(\mathrm{kg}) \text { at } 6 \\
\text { months }\end{array}$ & 1 & 142 & $\begin{array}{l}\text { Mean Difference (IV, Fixed, } \\
95 \% \text { CI) }\end{array}$ & $-0.50[-2.26,1.26]$ \\
\hline $\begin{array}{l}5.2 \text { Mean weight change }(\mathrm{kg}) \text { at } 12 \\
\text { months }\end{array}$ & 1 & 81 & $\begin{array}{l}\text { Mean Difference (IV, Fixed, } \\
95 \% \text { CI) }\end{array}$ & $0.70[-1.92,3.32]$ \\
\hline $\begin{array}{l}\text { 5.3 Mean percentage weight change } \\
\text { at } 6 \text { months }\end{array}$ & 1 & 142 & $\begin{array}{l}\text { Mean Difference (IV, Fixed, } \\
95 \% \text { CI) }\end{array}$ & $-0.70[-3.10,1.70]$ \\
\hline $\begin{array}{l}5.4 \text { Mean percentage weight change } \\
\text { at } 12 \text { months }\end{array}$ & 1 & 81 & $\begin{array}{l}\text { Mean Difference (IV, Fixed, } \\
\text { 95\% CI) }\end{array}$ & $0.00[-3.79,3.79]$ \\
\hline 5.5 Weight gain $>=1 \mathrm{~kg}$ at month 6 & 1 & 31 & $\begin{array}{l}\text { Odds Ratio (M-H, Fixed, } \\
95 \% \text { CI) }\end{array}$ & $0.39[0.09,1.67]$ \\
\hline $\begin{array}{l}5.6 \text { Weight gain }>=1 \mathrm{~kg} \text { at month } \\
12\end{array}$ & 1 & 26 & $\begin{array}{l}\text { Odds Ratio (M-H, Fixed, } \\
95 \% \text { CI) }\end{array}$ & $0.44[0.08,2.39]$ \\
\hline 5.7 Weight loss $>=1 \mathrm{~kg}$ at month 6 & 1 & 31 & $\begin{array}{l}\text { Odds Ratio (M-H, Fixed, } \\
95 \% \text { CI) }\end{array}$ & $9.24[0.44,195.69]$ \\
\hline $\begin{array}{l}5.8 \text { Weight loss }>=1 \mathrm{~kg} \text { at month } \\
12\end{array}$ & 1 & 26 & $\begin{array}{l}\text { Odds Ratio (M-H, Fixed, } \\
95 \% \text { CI) }\end{array}$ & $1.83[0.15,23.15]$ \\
\hline
\end{tabular}

\section{DMPA $150 \mathrm{mg} / \mathrm{mL}$ versus DMPA $450 \mathrm{mg} / \mathrm{mL}$}

\begin{tabular}{|l|l|l|l|l|}
\hline Outcome or Subgroup & Studies & Participants & Statistical Method & Effect Estimate \\
\hline $\begin{array}{l}\text { 6.1 Mean weight change }(\mathrm{kg}) \text { at } 6 \\
\text { months }\end{array}$ & 1 & 651 & $\begin{array}{l}\text { Mean Difference (IV, Fixed, } \\
95 \% \mathrm{CI})\end{array}$ & $0.01[-0.48,0.50]$ \\
\hline
\end{tabular}

\section{DMPA $150 \mathrm{mg} / \mathrm{mL}$ initiation after pregnancy: interval (>=20 weeks) versus postpartum (5 to 8 weeks)}

\begin{tabular}{|l|l|l|l|l|}
\hline Outcome or Subgroup & Studies & Participants & Statistical Method & Effect Estimate \\
\hline 7.1 Mean weight gain (lbs) at 1 year & 1 & 172 & $\begin{array}{l}\text { Mean Difference (IV, Fixed, } \\
\text { 95\% CI) }\end{array}$ & $2.30[-0.94,5.54]$ \\
\hline $\begin{array}{l}\text { 7.2 Mean weight gain (lbs) at 2 } \\
\text { years }\end{array}$ & 1 & 64 & $\begin{array}{l}\text { Mean Difference (IV, Fixed, } \\
95 \% \text { CI) }\end{array}$ & $1.60[-4.79,7.99]$ \\
\hline
\end{tabular}




\section{DMPA-IM 150 mg versus DMPA-SC 104 mg}

\begin{tabular}{|l|l|l|l|l|}
\hline Outcome or Subgroup & Studies & Participants & Statistical Method & Effect Estimate \\
\hline $\begin{array}{l}\text { 8.1 Mean weight change (kg) at } 36 \\
\text { months }\end{array}$ & 1 & 121 & $\begin{array}{l}\text { Mean Difference (IV, Fixed, } \\
95 \% \text { CI) }\end{array}$ & $1.30[-1.78,4.38]$ \\
\hline
\end{tabular}

\section{DMPA $150 \mathrm{mg} / \mathrm{mL}$ versus NET-EN 200 mg (60-day intervals)}

\begin{tabular}{|l|l|l|l|l|}
\hline Outcome or Subgroup & Studies & Participants & Statistical Method & Effect Estimate \\
\hline $\begin{array}{l}\text { 9.1 Mean weight change }(\mathrm{kg}) \text { at } 12 \\
\text { months }\end{array}$ & 1 & 1162 & $\begin{array}{l}\text { Mean Difference (IV, Fixed, } \\
95 \% \text { CI) }\end{array}$ & 0.20 [-0.63, 1.03] \\
\hline $\begin{array}{l}\text { 9.2 Mean weight change }(\mathrm{kg}) \text { at } 24 \\
\text { months }\end{array}$ & 1 & 604 & $\begin{array}{l}\text { Mean Difference (IV, Fixed, } \\
95 \% \text { CI) }\end{array}$ & $0.00[-1.39,1.39]$ \\
\hline 9.3 Mean weight change at 1 year & 1 & 201 & $\begin{array}{l}\text { Mean Difference (IV, Fixed, } \\
95 \% \text { CI) }\end{array}$ & $0.80[-0.10,1.70]$ \\
\hline
\end{tabular}

\section{NET-EN $200 \mathrm{mg}$ : 60-day intervals versus 3 intervals of 60 days then 84- day intervals}

\begin{tabular}{|l|l|l|l|l|}
\hline Outcome or Subgroup & Studies & Participants & Statistical Method & Effect Estimate \\
\hline $\begin{array}{l}10.1 \text { Mean weight change }(\mathrm{kg}) \text { at } 12 \\
\text { months }\end{array}$ & 1 & 822 & $\begin{array}{l}\text { Mean Difference (IV, Fixed, } \\
95 \% \text { CI) }\end{array}$ & $0.00[-0.71,0.71]$ \\
\hline $\begin{array}{l}10.2 \text { Mean weight change }(\mathrm{kg}) \text { at } 24 \\
\text { months }\end{array}$ & 1 & 453 & $\begin{array}{l}\text { Mean Difference (IV, Fixed, } \\
95 \% \text { CI) }\end{array}$ & $-0.10[-1.35,1.15]$ \\
\hline
\end{tabular}

\section{DMPA $150 \mathrm{mg} / \mathrm{mL}$ versus non-hormonal IUD}

\begin{tabular}{|c|c|c|c|c|}
\hline Outcome or Subgroup & Studies & Participants & Statistical Method & Effect Estimate \\
\hline $\begin{array}{l}11.1 \text { Mean weight change }(\mathrm{kg}) \text { at } \\
120 \text { months }\end{array}$ & 1 & 100 & $\begin{array}{l}\text { Mean Difference (IV, Fixed, } \\
95 \% \text { CI) }\end{array}$ & $-0.30[-0.83,0.23]$ \\
\hline $\begin{array}{l}11.2 \text { Mean weight change }(\mathrm{kg}) \text { at } 1 \\
\text { year by baseline BMI }\end{array}$ & 1 & 758 & $\begin{array}{l}\text { Mean Difference (IV, Fixed, } \\
95 \% \text { CI) }\end{array}$ & $2.28[1.79,2.77]$ \\
\hline 11.2.1 BMI $<25 \mathrm{~kg} / \mathrm{m}^{2}$ & 1 & 452 & $\begin{array}{l}\text { Mean Difference (IV, Fixed, } \\
95 \% \text { CI) }\end{array}$ & $2.50[1.90,3.10]$ \\
\hline 11.2.2 BMI 25 to $29.9 \mathrm{~kg} / \mathrm{m}^{2}$ & 1 & 218 & $\begin{array}{l}\text { Mean Difference (IV, Fixed, } \\
\text { 95\% CI) }\end{array}$ & $2.10[1.16,3.04]$ \\
\hline 11.2.3 BMI >= $30 \mathrm{~kg} / \mathrm{m}^{2}$ & 1 & 88 & $\begin{array}{l}\text { Mean Difference (IV, Fixed, } \\
\text { 95\% CI) }\end{array}$ & $0.70[-1.26,2.66]$ \\
\hline $\begin{array}{l}11.3 \text { Mean weight change }(\mathrm{kg}) \text { at } 2 \\
\text { years by baseline BMI }\end{array}$ & 1 & 758 & $\begin{array}{l}\text { Mean Difference (IV, Fixed, } \\
95 \% \mathrm{CI})\end{array}$ & $2.71[2.12,3.30]$ \\
\hline 11.3.1 BMI $<25 \mathrm{~kg} / \mathrm{m}^{2}$ & 1 & 452 & $\begin{array}{l}\text { Mean Difference (IV, Fixed, } \\
\text { 95\% CI) }\end{array}$ & $2.70[2.02,3.38]$ \\
\hline 11.3.2 BMI 25 to $29.9 \mathrm{~kg} / \mathrm{m}^{2}$ & 1 & 218 & $\begin{array}{l}\text { Mean Difference (IV, Fixed, } \\
95 \% \text { CI) }\end{array}$ & $3.00[1.73,4.27]$ \\
\hline 11.3.3 $\mathrm{BMI}>=30 \mathrm{~kg} / \mathrm{m}^{2}$ & 1 & 88 & $\begin{array}{l}\text { Mean Difference (IV, Fixed, } \\
95 \% \text { CI) }\end{array}$ & $1.50[-1.33,4.33]$ \\
\hline
\end{tabular}




\begin{tabular}{|c|l|l|l|l|}
\hline Outcome or Subgroup & Studies & Participants & Statistical Method & Effect Estimate \\
\hline $\begin{array}{l}\text { 11.4 Mean weight change (kg) at } 3 \\
\text { years by baseline BMI }\end{array}$ & 1 & 758 & $\begin{array}{l}\text { Mean Difference (IV, Fixed, } \\
95 \% \text { CI) }\end{array}$ & 3.17 [2.51, 3.83] \\
\hline $11.4 .1 \mathrm{BMI}<25 \mathrm{~kg} / \mathrm{m}^{2}$ & 1 & 452 & $\begin{array}{l}\text { Mean Difference (IV, Fixed, } \\
95 \% \mathrm{CI})\end{array}$ & 3.30 [2.52, 4.08] \\
\hline $11.4 .2 \mathrm{BMI} 25$ to $29.9 \mathrm{~kg} / \mathrm{m}^{2}$ & 1 & 218 & $\begin{array}{l}\text { Mean Difference (IV, Fixed, } \\
95 \% \text { CI) }\end{array}$ & $3.20[1.82,4.58]$ \\
\hline $11.4 .3 \mathrm{BMI}>=30 \mathrm{~kg} / \mathrm{m}^{2}$ & 1 & 88 & $\begin{array}{l}\text { Mean Difference (IV, Fixed, } \\
95 \% \mathrm{CI})\end{array}$ & $1.30[-1.56,4.16]$ \\
\hline
\end{tabular}

\section{Norplant versus DMPA $150 \mathrm{mg} / \mathrm{mL}$}

\begin{tabular}{|l|l|l|l|l|}
\hline Outcome or Subgroup & Studies & Participants & Statistical Method & Effect Estimate \\
\hline $\begin{array}{l}12.1 \text { Mean weight change }(\mathrm{kg}) \text { at } 1 \\
\text { year }\end{array}$ & 1 & 100 & $\begin{array}{l}\text { Mean Difference (IV, Fixed, } \\
95 \% \mathrm{CI})\end{array}$ & $-0.87[-1.86,0.12]$ \\
\hline
\end{tabular}

\section{Norplant versus non-hormonal IUD}

\begin{tabular}{|l|l|l|l|l|}
\hline Outcome or Subgroup & Studies & Participants & Statistical Method & Effect Estimate \\
\hline $\begin{array}{l}\text { 13.1 Mean weight change }(\mathrm{kg}) \text { at } 6 \\
\text { months }\end{array}$ & 1 & 99 & $\begin{array}{l}\text { Mean Difference (IV, Fixed, } \\
\text { 95\% CI) }\end{array}$ & 0.47 [0.29, 0.65] \\
\hline $\begin{array}{l}13.2 \text { Mean weight change }(\mathrm{kg}) \text { at } 1 \\
\text { year }\end{array}$ & 1 & 324 & $\begin{array}{l}\text { Mean Difference (IV, Fixed, } \\
\text { 95\% CI) }\end{array}$ & 1.10 [0.36, 1.84] \\
\hline $\begin{array}{l}13.3 \text { Mean weight change }(\mathrm{kg}) \text { at } 3 \\
\text { years }\end{array}$ & 1 & 190 & $\begin{array}{l}\text { Mean Difference (IV, Fixed, } \\
\text { 95\% CI) }\end{array}$ & $0.90[-0.39,2.19]$ \\
\hline
\end{tabular}

\section{Norplant versus barrier, 'local', or no contraceptive method}

\begin{tabular}{|l|l|l|l|l|}
\hline Outcome or Subgroup & Studies & Participants & Statistical Method & Effect Estimate \\
\hline $\begin{array}{l}14.1 \text { Mean weight change }(\mathrm{kg}) \text { at } 6 \\
\text { months }\end{array}$ & 1 & 97 & $\begin{array}{l}\text { Mean Difference (IV, Fixed, } \\
95 \% \text { CI })\end{array}$ & $0.74[0.52,0.96]$ \\
\hline
\end{tabular}

\section{Norplant versus 2-rod LNG}

\begin{tabular}{|l|l|l|l|l|}
\hline Outcome or Subgroup & Studies & Participants & Statistical Method & Effect Estimate \\
\hline $\begin{array}{l}15.1 \text { Mean weight change }(\mathrm{kg}) \text { at } 1 \\
\text { year }\end{array}$ & 1 & 1196 & $\begin{array}{l}\text { Mean Difference (IV, Fixed, } \\
95 \% \text { CI) }\end{array}$ & 0.09 [-0.33, 0.51] \\
\hline $\begin{array}{l}\text { 15.2 Mean weight change (kg) at 3 } \\
\text { years }\end{array}$ & 1 & 922 & $\begin{array}{l}\text { Mean Difference (IV, Fixed, } \\
95 \% \text { CI) }\end{array}$ & $0.00[-0.60,0.60]$ \\
\hline $\begin{array}{l}15.3 \text { Mean weight change (kg) at 5 } \\
\text { years }\end{array}$ & 1 & 614 & $\begin{array}{l}\text { Mean Difference (IV, Fixed, } \\
95 \% \text { CI) }\end{array}$ & $0.60[-0.13,1.33]$ \\
\hline
\end{tabular}




\section{Norplant versus COC}

\begin{tabular}{|l|l|l|l|l|}
\hline Outcome or Subgroup & Studies & Participants & Statistical Method & Effect Estimate \\
\hline $\begin{array}{l}16.1 \text { Mean weight change }(\mathrm{kg}) \text { at } 1 \\
\text { year }\end{array}$ & 1 & 226 & $\begin{array}{l}\text { Mean Difference (IV, Fixed, } \\
95 \% \text { CI) }\end{array}$ & 1.10 [-0.13, 2.33] \\
\hline $\begin{array}{l}16.2 \text { Mean weight change (kg) at } 3 \\
\text { years }\end{array}$ & 1 & 132 & $\begin{array}{l}\text { Mean Difference (IV, Fixed, } \\
95 \% \text { CI) }\end{array}$ & Not estimable \\
\hline
\end{tabular}

\section{LNG-IUS versus non-hormonal IUD}

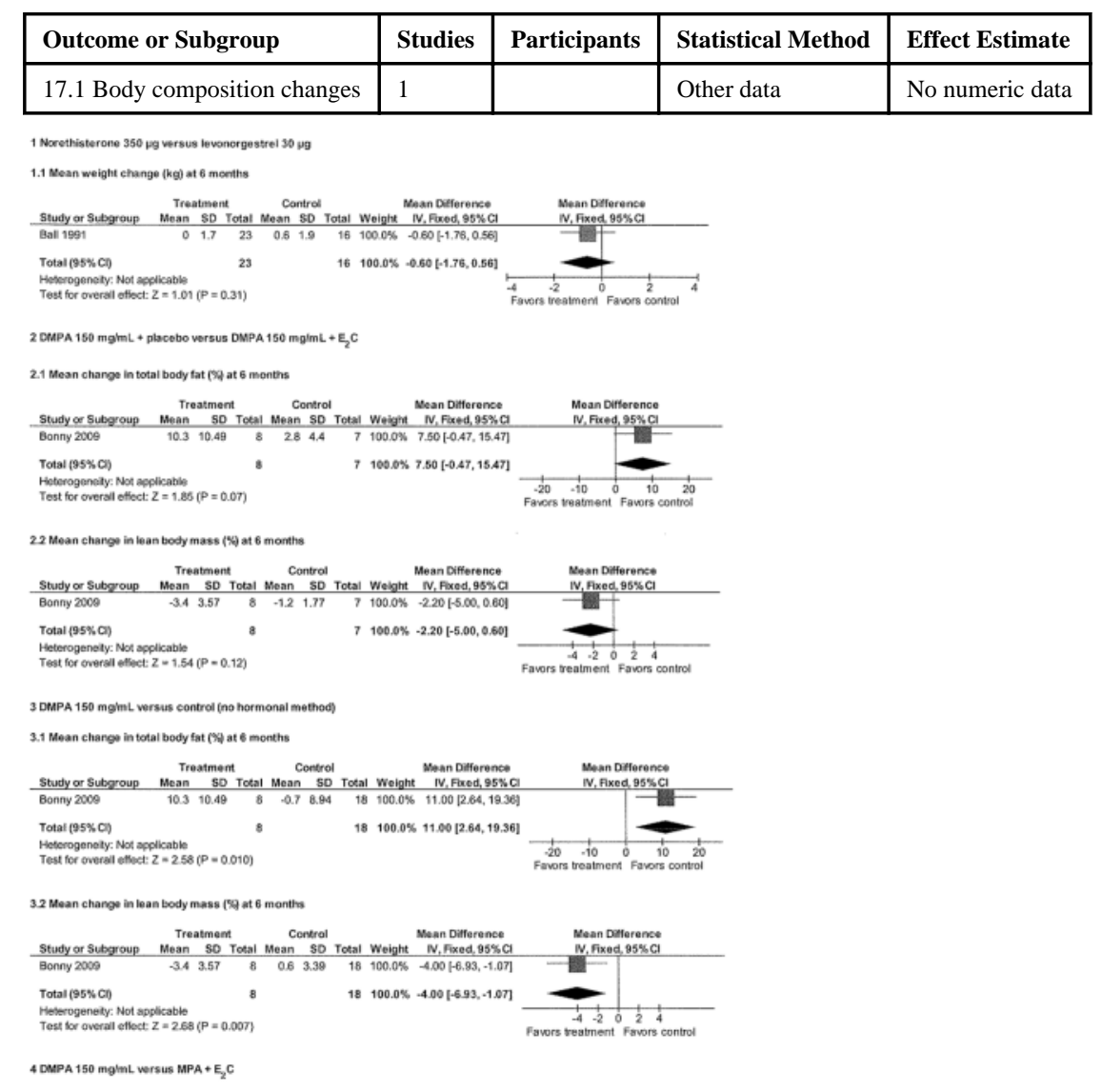




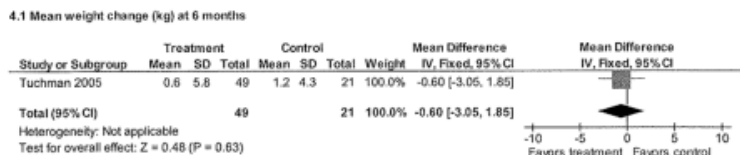

4.2 Wean weighte change $(\mathrm{kg})$ at 12 months

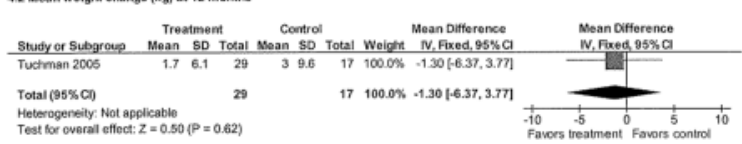

Teses tor overal effect: $Z=0.50(P=0.62$

4.3 Mean percentage weight change at 6 moments

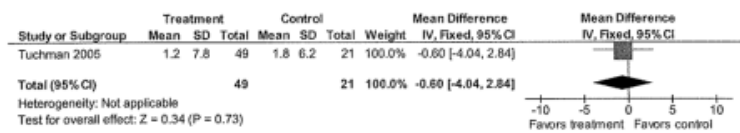

44 Mean percertage weighte change at 12 months

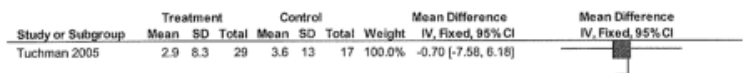

Tot 195\% C1)

Total (95\%Cl)
Heterogeneity Not appicabie
Test for overall eflect $Z=0.20(P=0.84)$

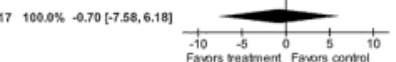

5 DMPA $150 \mathrm{mg} / \mathrm{mL}$ versus $C O C$

5.1 Mean weight change (kg) at 6 months

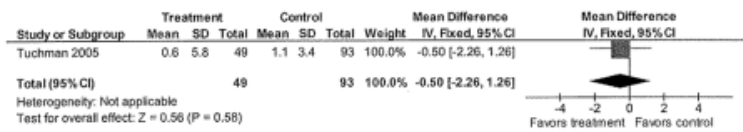

5.2 Moan weight eranges $(\mathrm{kg})$ at 12 monnts

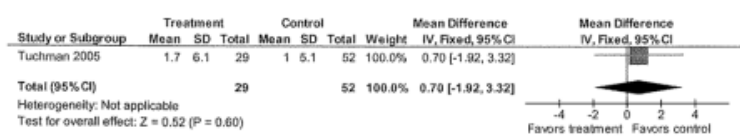

Heterogenenily: Not applicable
Test for owerall eflect: $Z=0.52(P=0.60)$

5.3 Mean percentage woight change at 6 months

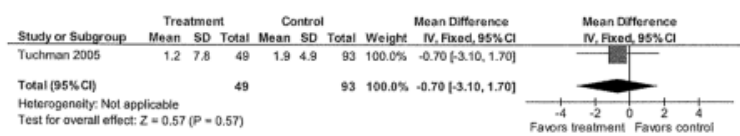

Heterogenenity N Not applicable
Test for overall eflect: $Z=0.57(P=0.57)$

5.4 Mean percertagge woight change at 12 months

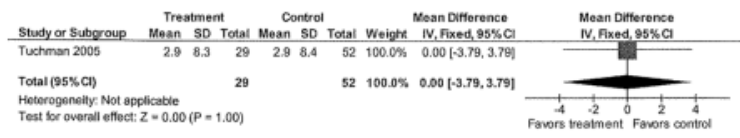

5.5 Weight gain $>=1 \mathrm{~kg}$ at monesh 6

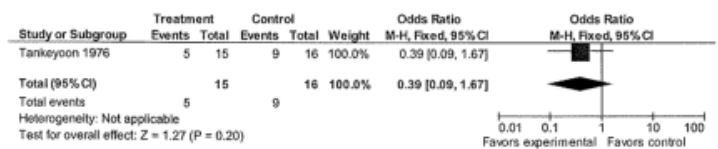

5.5 Weight gain $x=1 \mathrm{~kg}$ at moraht 12

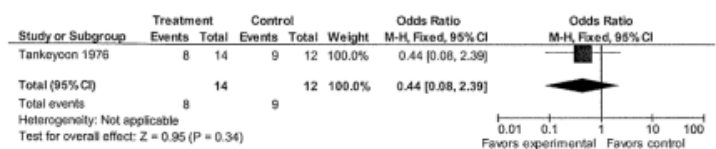




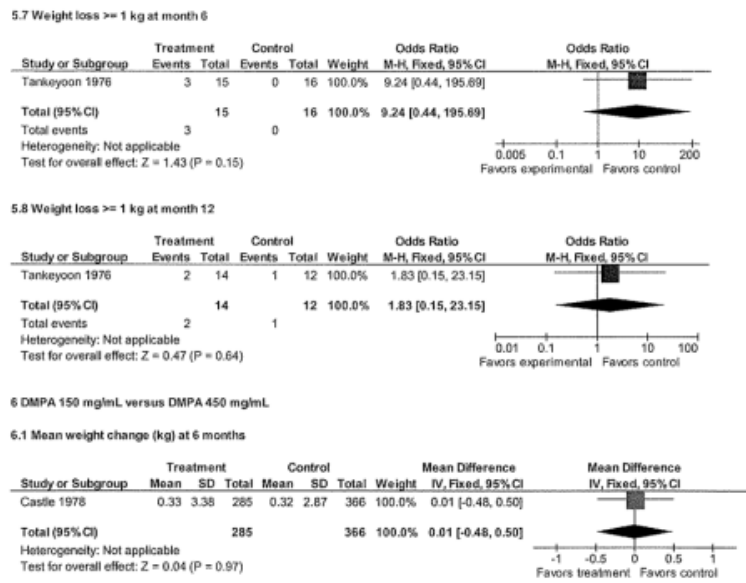

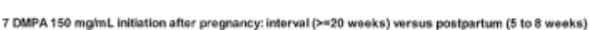

7.1 Mean weight gain (lbs) at 1 year

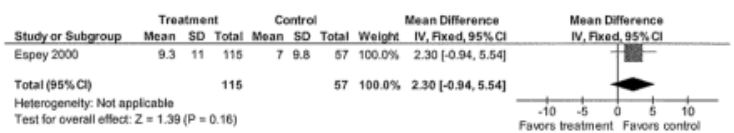

72 Mean welght gain (libs) at 2 years

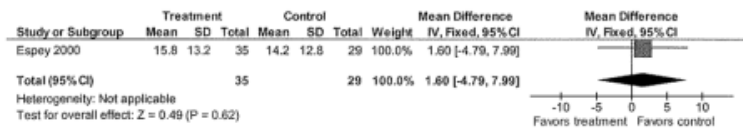

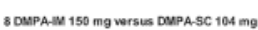

8.1 Mean woight elanger (kg) at 36 monkhs

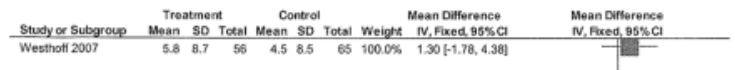

Totet (95\%c)

Heterogenety: Not applicabio

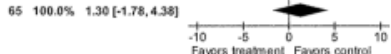

9 DMPA $150 \mathrm{mg} \mathrm{mL}$ versus NET-EN $200 \mathrm{mg}$ (60-day intervals)

9.1 Mean weight echange $(k \mathrm{~kg})$ at 12 monxhs

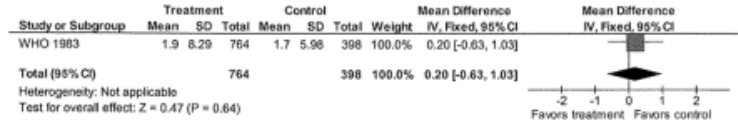

9.2 Mean woight ellange (kg) at 24 moenhs

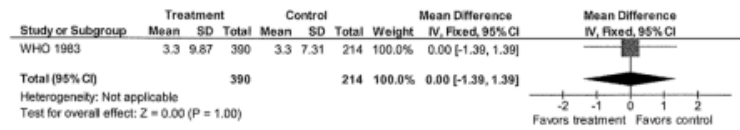

9.3 Mean weighte change at 1 year

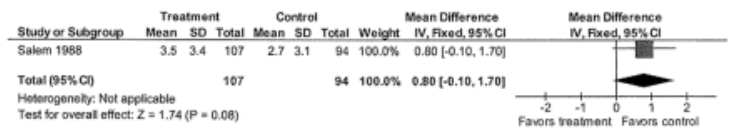

10 NET-EN $200 \mathrm{mg}$ : 60 -day intervals versus 3 intervals of 50 days then 84-day intervals

10.1 Mean weight change of $x$ gif at 12 months

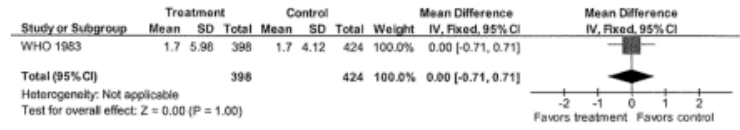




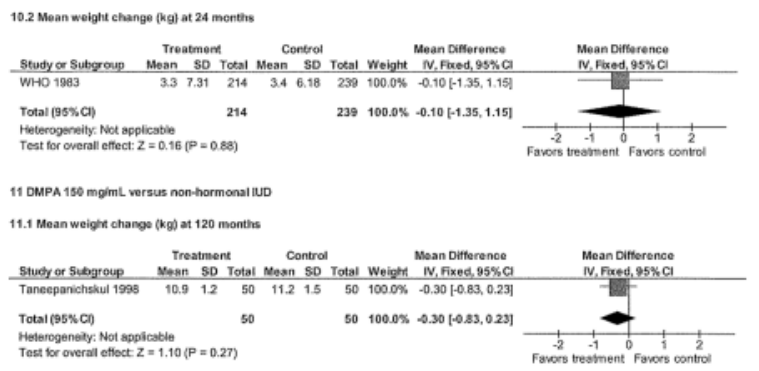

11.2 Mean weighte change (xgg) at 1 year by baseline $\mathrm{BMI}$

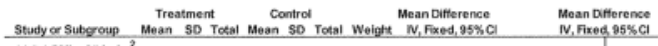

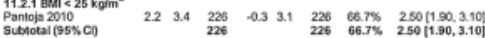

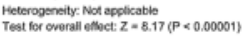

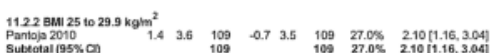

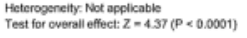

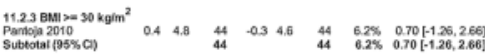

(2)

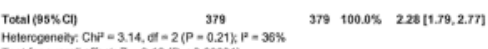

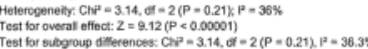

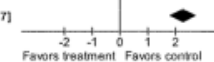

11.3 Moan woight change (kg) at 2 years by basefine Bat

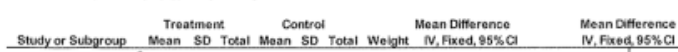

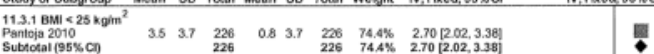

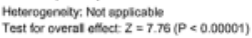

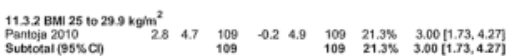

Heterogenoty; Not appicabib

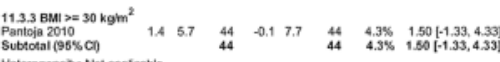

Heterogoeneaty: Not applcable
Test tor overall elfoct $Z=1.04(P=0.30)$

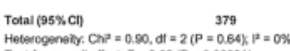

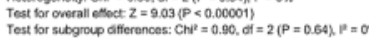

11.4 Mean weight change $(\mathrm{kg})$ at 3 years by baseline BMa

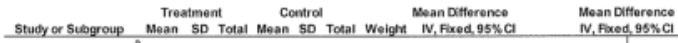

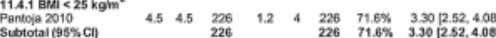

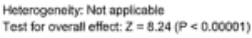

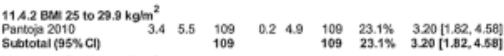

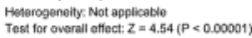

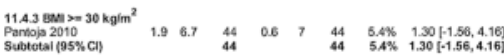

Heterogeneity: Not applicabie
Test tor overal effect: $Z=0.89(P=0.37)$

Total (955) (a) 3790

Heletrogeneity: $\mathrm{CH}^{2}=1.75, \mathrm{df}=2(\mathrm{P}=0.42) ; \mathrm{I}^{2}=0 \mathrm{~N}$

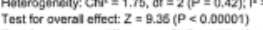

$=2(P=0.42), P=0.4$

12 Noeplare versus DMPA $150 \mathrm{mg} / \mathrm{mL}$. 


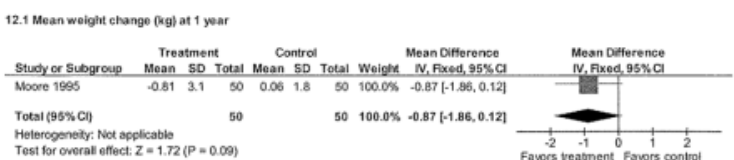

13 Norplant versus non-hormonal IUD

13.1 Mean weight change (kg) at 6 months

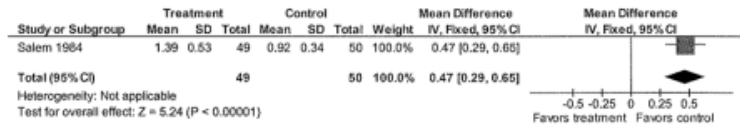

13.2 Mean weight change (kgl) at 1 year

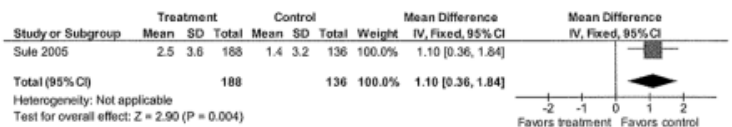

18.3 Mean weight change (kgl) at 3 yoars

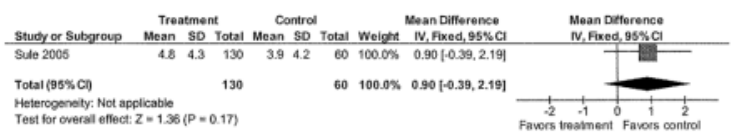

14 Norplant versus barrier, local', or no contracopteve method

14.1 Mean weight change (kg) at 6 months

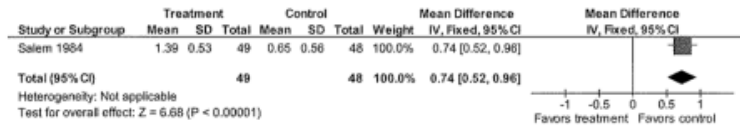

15 Norplant wersus 2+od LNG

15.1 Mean woigh change (kgl) at 1 year

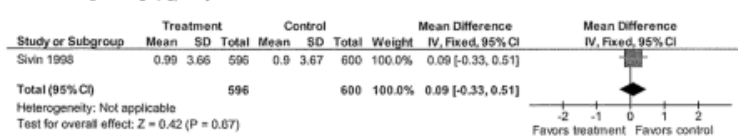

Tost tor coreral effect: $z=0.02(P=0.67)$

15.2 Mean weight change $(\mathrm{kg})$ at 3 years

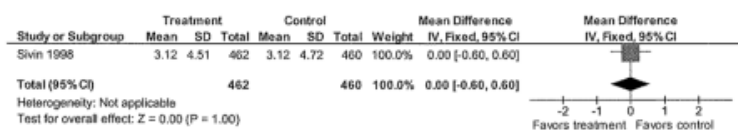

15.3 Mean weight clange (kg) at 5 years

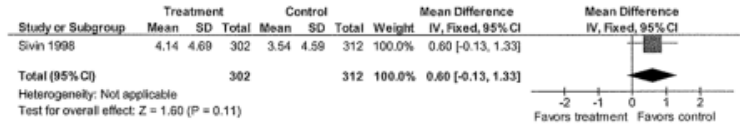

16 Norplant versus COC

16.1 Mean woight changes $(\mathrm{kgg})$ at 1 year

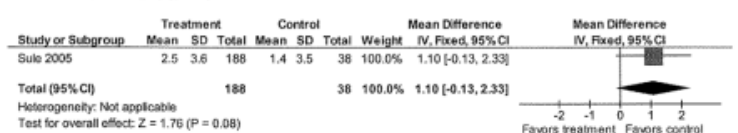

16.2 Moan weight changes (kg) at 3 yeare

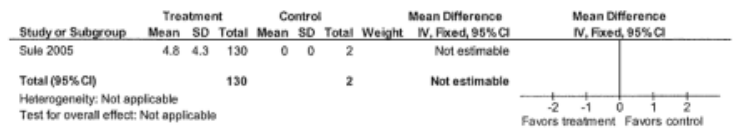

17 LNGIUS versus nonthormonal IUD 


\begin{tabular}{|c|c|c|c|c|}
\hline Study ID & Body composition assessment & $\begin{array}{l}\text { LNG IUS group } \\
(\operatorname{men} \neq \mathrm{SD})\end{array}$ & $\begin{array}{l}\text { TCusso A IUD group } \\
\text { (mean } \& \text { SD) }\end{array}$ & $\begin{array}{l}\text { Reported P value } \\
\text { Wileoxon paired tese }\end{array}$ \\
\hline \multirow{4}{*}{ Dal'Ava 2012} & Change in weighn (kg) & $2.9 \pm 5.7$ & $1.4 \pm 4.4$ & 0.068 \\
\hline & Change in centrat-paripheral fat ratio $(\mathrm{X})$ & $-1.6 \pm 18.7$ & $-0.2 \pm 11.6$ & 0.364 \\
\hline & Percert change in fat mass & $2.5 \pm 8.0$ & $-1.3 \pm 6.9$ & 0.029 \\
\hline & Percert change in ban mass & $-1.4 \pm 4.7$ & $1.0 \pm 3.8$ & 0.027 \\
\hline
\end{tabular}




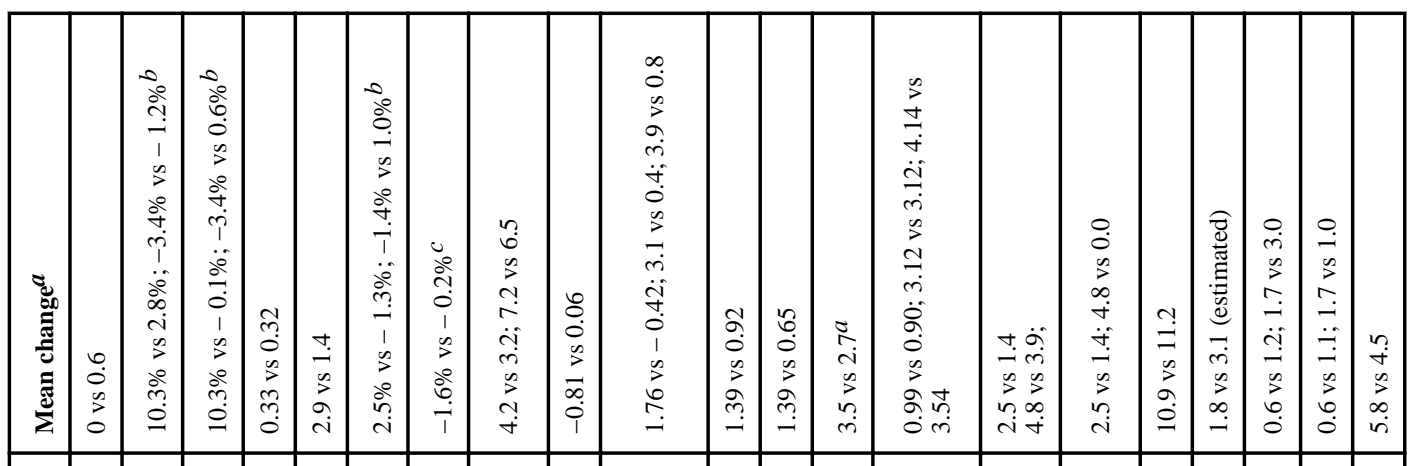

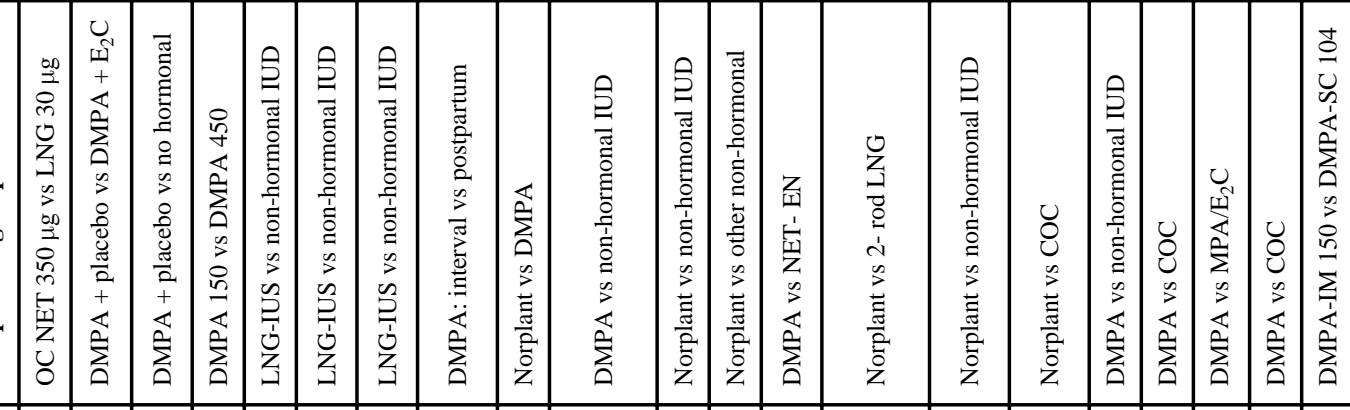

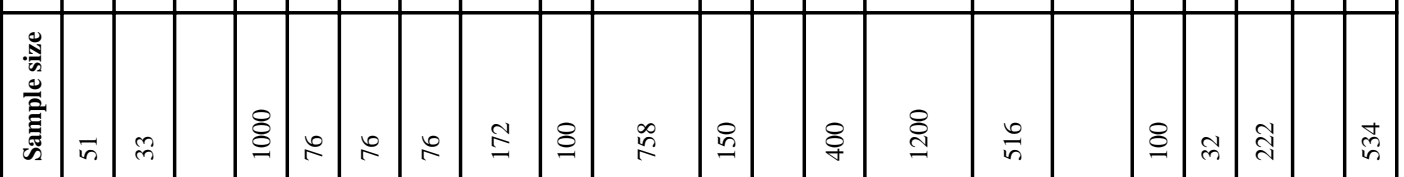

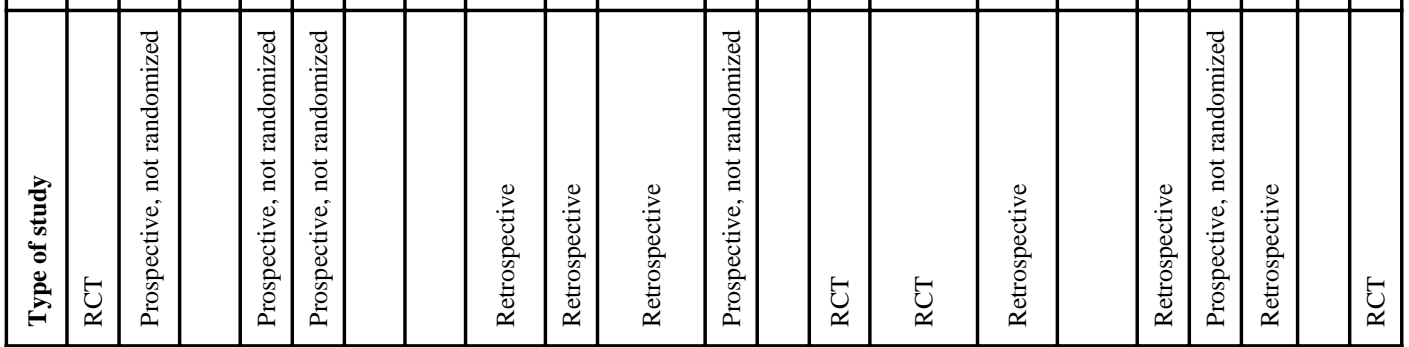

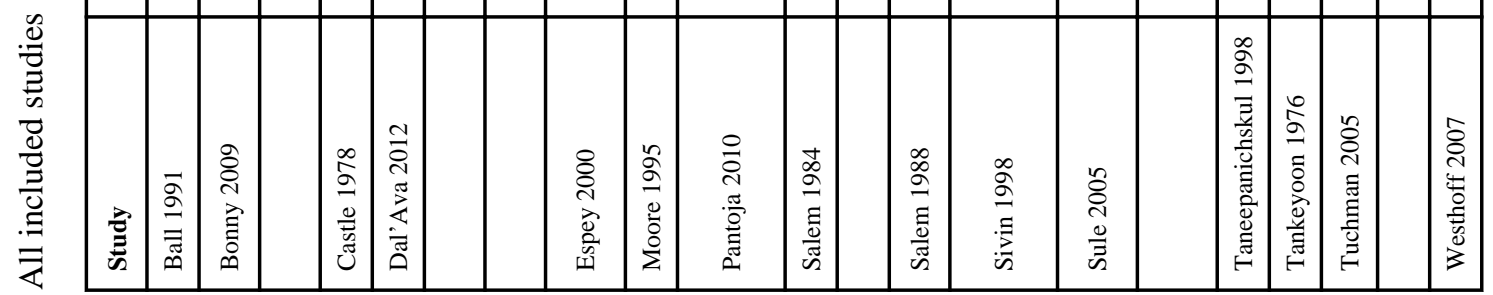




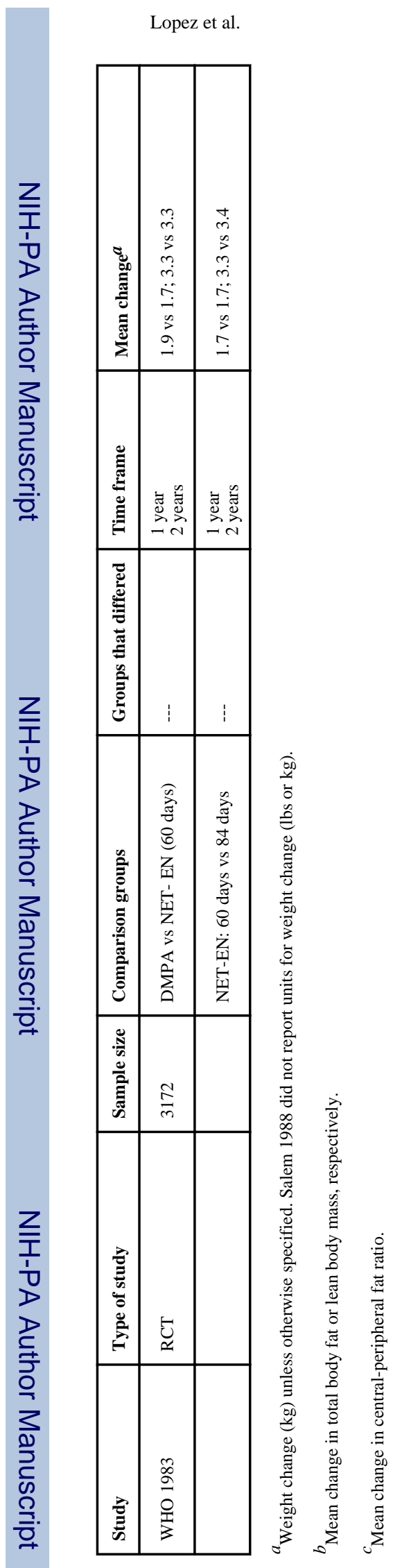

Page 32 
Sensitivity analysis

\begin{tabular}{|c|c|c|c|c|}
\hline Study ${ }^{a}$ & Type of study & Comparison groups & Groups differed significantly & $\begin{array}{l}\text { Mean difference } \\
(95 \% \mathrm{CI})\end{array}$ \\
\hline Ball 1991 & RCT & $\begin{array}{l}\text { OCs: NET } 350 \mu \mathrm{g} \text { vs LNG } 30 \\
\mu \mathrm{g}\end{array}$ & --- & --- \\
\hline Bonny 2009 & Prospective, non- randomized & $\begin{array}{l}\text { DMPA }+ \text { placebo vs DMPA }+ \\
E_{2} C \text { or vs no hormonal method }\end{array}$ & DMPA + placebo vs no hormonal & $\begin{array}{l}11.00(2.64 \text { to } \\
19.36) ;-4.00 \\
(-6.93 \text { to }- \\
1.07)^{b}\end{array}$ \\
\hline Dal'Ava 2012 & Prospective, non- randomized & $\begin{array}{l}\text { LNG-IUS vs non-hormonal } \\
\text { IUD }\end{array}$ & LNG-IUS vs non-hormonal IUD & $\begin{array}{l}2.5 \% \text { vs }-1.3 \% \\
-1.4 \% \text { vs } 1.0 \% b\end{array}$ \\
\hline Salem 1984 & Prospective, non- randomized & $\begin{array}{l}\text { Implant vs non-hormonal IUD } \\
\text { or vs no hormonal method }\end{array}$ & $\begin{array}{l}\text { Implant vs non-hormonal IUD or vs } \\
\text { other non- hormonal }\end{array}$ & $\begin{array}{l}0.47(0.29 \text { to } \\
0.65) ; 0.74(0.52 \\
\text { to } 0.96)^{c}\end{array}$ \\
\hline Sivin 1998 & RCT & $\begin{array}{l}\text { Implant (6 capsules) vs } \\
\text { implant ( } 2 \text {-rods) }\end{array}$ & --- & --- \\
\hline
\end{tabular}

${ }^{a}$ Excludes retrospective chart reviews and studies withloss to follow up or discontinuation $>=25 \%$.

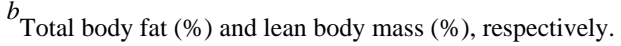

${ }^{c}$ Weight change (kg). 
Quality of evidence by contraceptive method

\begin{tabular}{|c|c|c|c|}
\hline Study & Comparison groups & Mean difference $(95 \% \mathrm{CI}) *$ & Quality of evidence $^{* *}$ \\
\hline \multicolumn{4}{|l|}{ Progestin-only pills } \\
\hline Ball 1991 & OC NET $350 \mu \mathrm{g}$ vs LNG $30 \mu \mathrm{g}$ & --- & High \\
\hline \multicolumn{4}{|l|}{ DMPA } \\
\hline \multirow{2}{*}{ WHO 1983} & DMPA vs NET-EN (60 days) & --- & \multirow{2}{*}{ High } \\
\hline & NET-EN: 60 days vs 84 days & --- & \\
\hline Salem 1988 & DMPA vs NET-EN & --- & High \\
\hline \multirow{2}{*}{ Bonny 2009} & DMPA + placebo vs DMPA $+\mathrm{E}_{2} \mathrm{C}$ & --- & \multirow{2}{*}{ Moderate } \\
\hline & DMPA + placebo vs no hormonal & $11.00(2.64$ to 19.36$) ;-4.00(-6.93 \text { to }-1.07)^{a}$ & \\
\hline Westhoff 2007 & DMPA-IM 150 vs DMPA-SC 104 & --- & Moderate \\
\hline Castle 1978 & DMPA 150 vs DMPA 450 & --- & Low \\
\hline Pantoja 2010 & DMPA vs non-hormonal IUD & $3.17(2.51 \text { to } 3.83)^{b}$ & Low \\
\hline Tankeyoon 1976 & DMPA vs COC & --- & Low \\
\hline Taneepanichskul 1998 & DMPA vs non-hormonal IUD & --- & Very low \\
\hline \multirow{2}{*}{ Tuchman 2005} & DMPA vs MPA/E $\mathrm{E}_{2} \mathrm{C}$ & --- & \multirow{2}{*}{ Very low } \\
\hline & DMPA vs COC & --- & \\
\hline Espey 2000 & DMPA: interval vs postpartum & --- & Very low \\
\hline \multicolumn{4}{|l|}{ Norplant } \\
\hline Sivin 1998 & Norplant vs 2-rod LNG & --- & High \\
\hline \multirow{2}{*}{ Salem 1984} & Norplant vs non-hormonal IUD & $0.47(0.29 \text { to } 0.65)^{b}$ & \multirow{2}{*}{ Moderate } \\
\hline & Norplant vs other non- hormonal & $0.74(0.52 \text { to } 0.96)^{b}$ & \\
\hline Moore 1995 & Norplant vs DMPA & --- & Low \\
\hline \multirow{2}{*}{ Sule 2005} & Norplant vs non-hormonal IUD & $1.10(0.36 \text { to } 1.84)^{b}$ & \multirow{2}{*}{ Very low } \\
\hline & Norplant vs COC & --- & \\
\hline \multicolumn{4}{|c|}{ Levonorgestrel-releasing IUS } \\
\hline Dal'Ava 2012 & LNG-IUS vs non-hormonal IUD & $2.5 \%$ vs $-1.3 \% ;-1.4 \%$ vs $1.0 \%^{a}$ & Moderate \\
\hline \multicolumn{4}{|c|}{$\begin{array}{l}\text { ** Grades initially based on study design }(\mathrm{RCT}=\text { high; prospective non-randomized }=\text { moderate; retrospective }=\text { low }) \text {. Downgraded if losses } \\
>=25 \% \text { or if cases were inappropriately excluded. }\end{array}$} \\
\hline
\end{tabular}




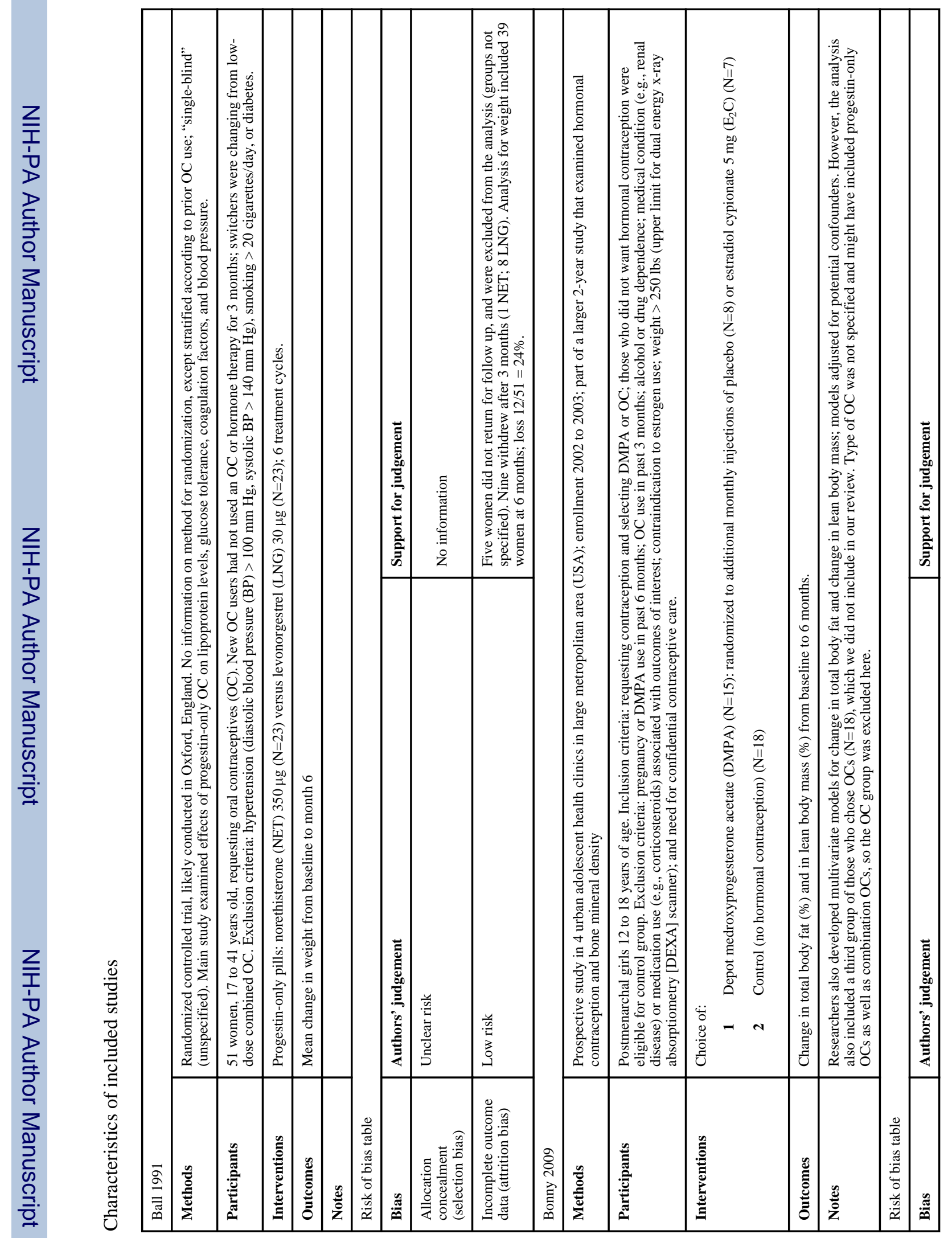




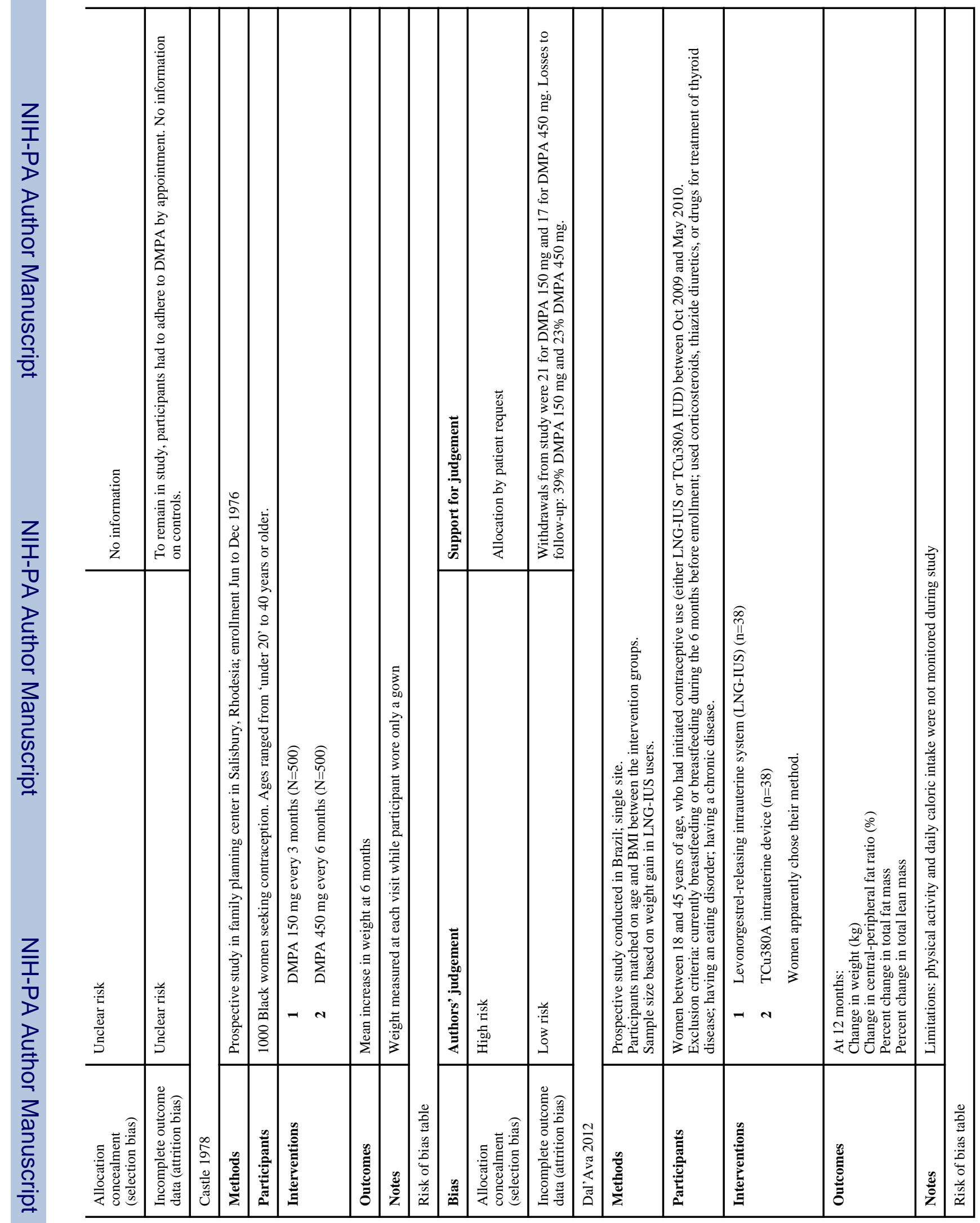




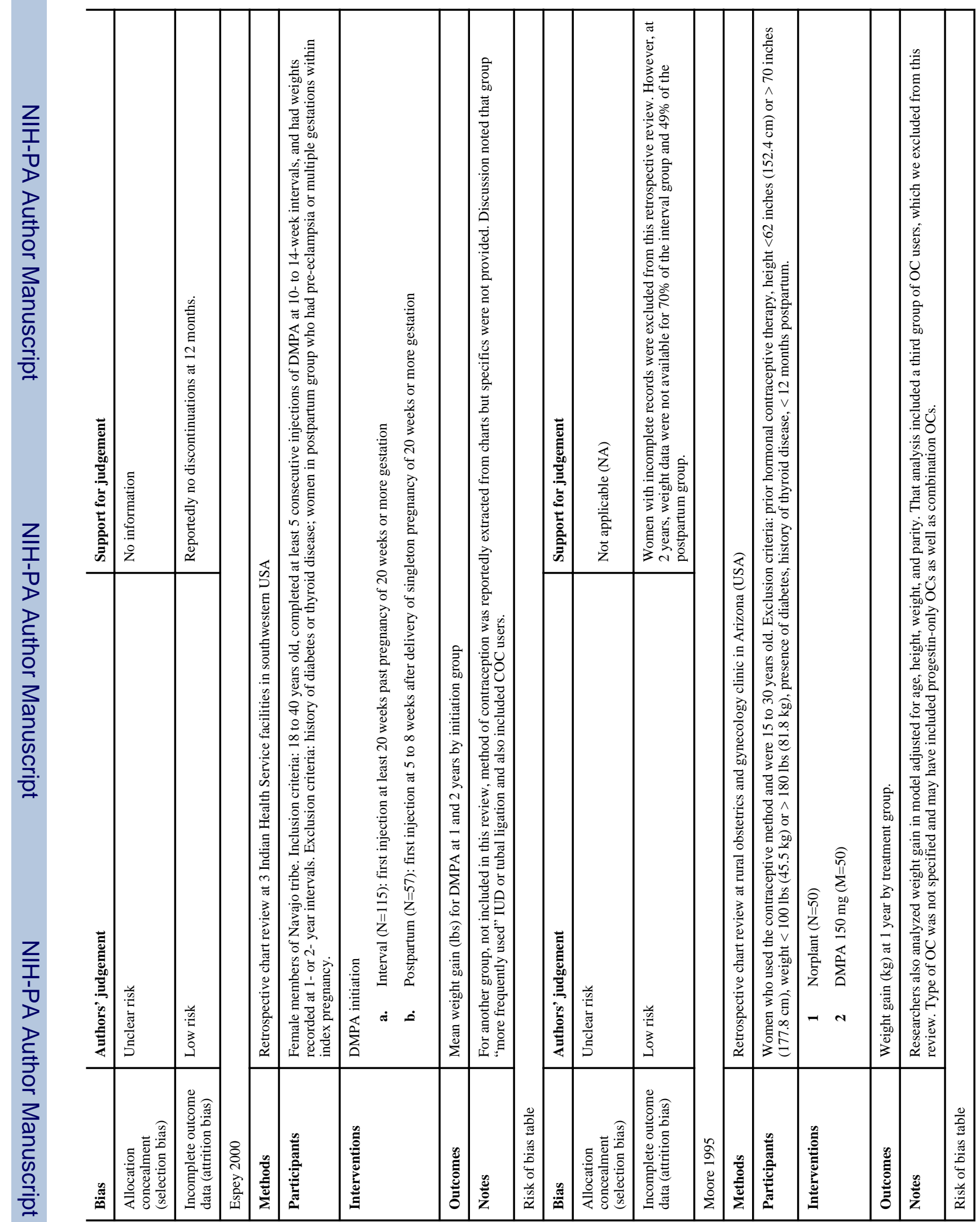




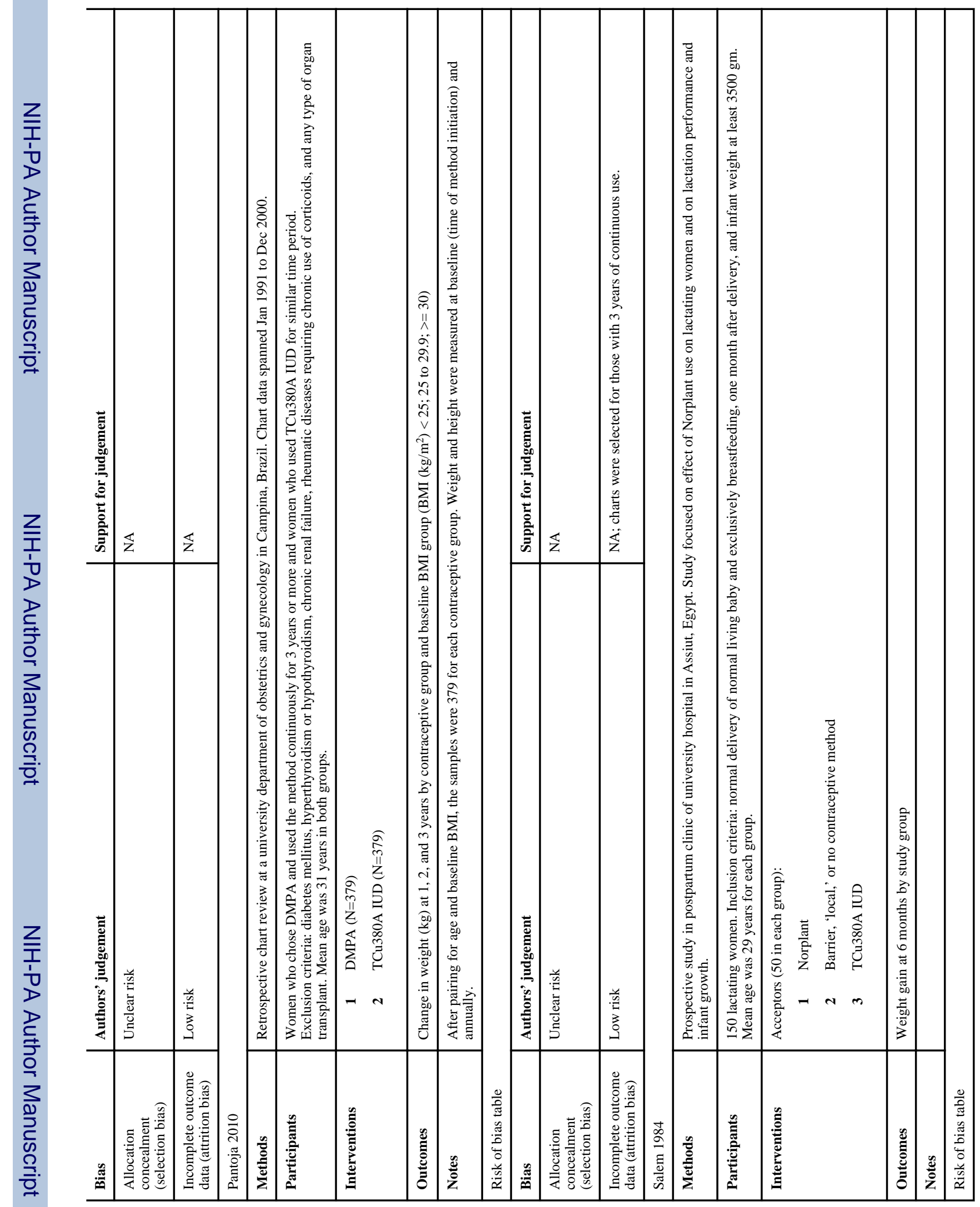




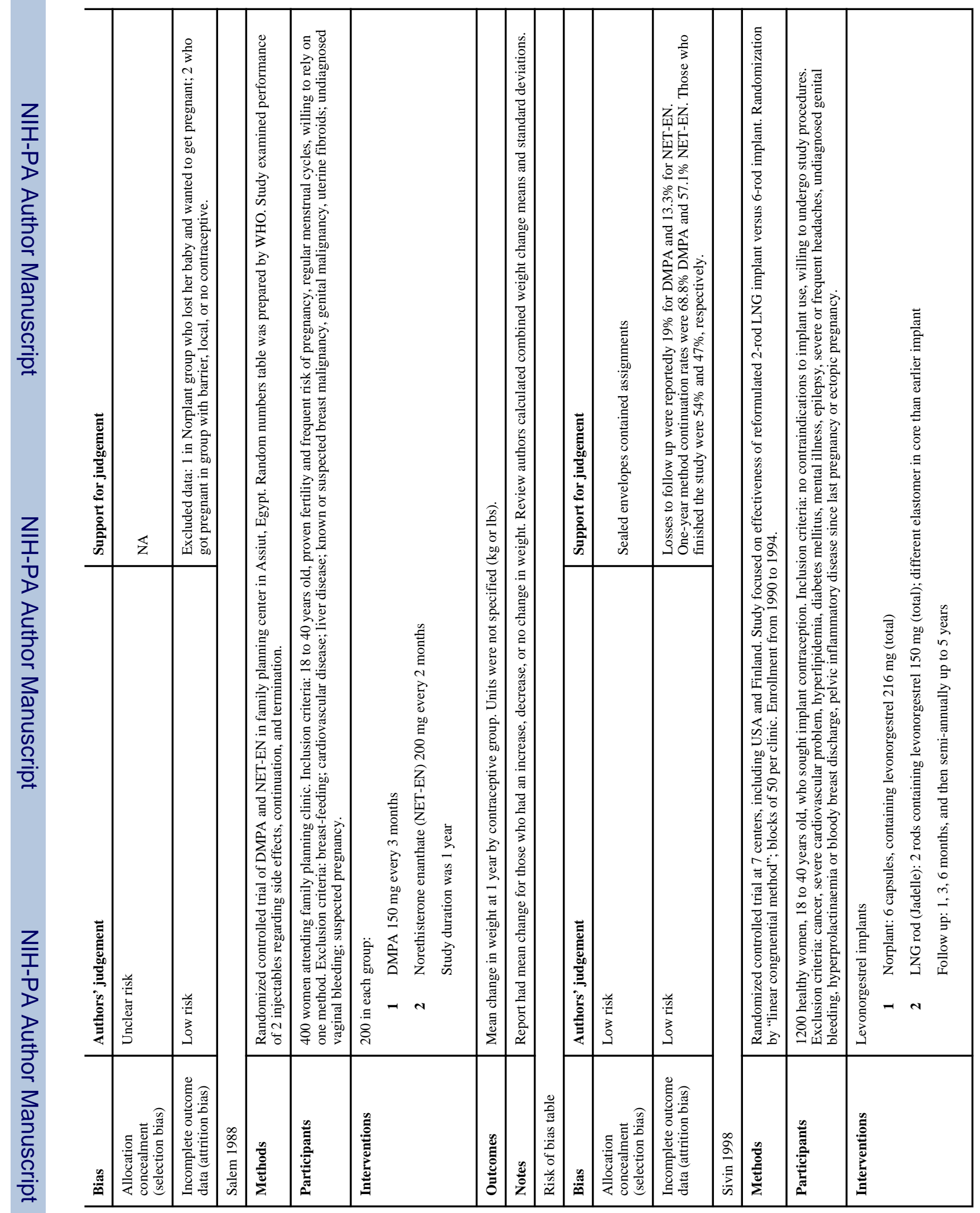




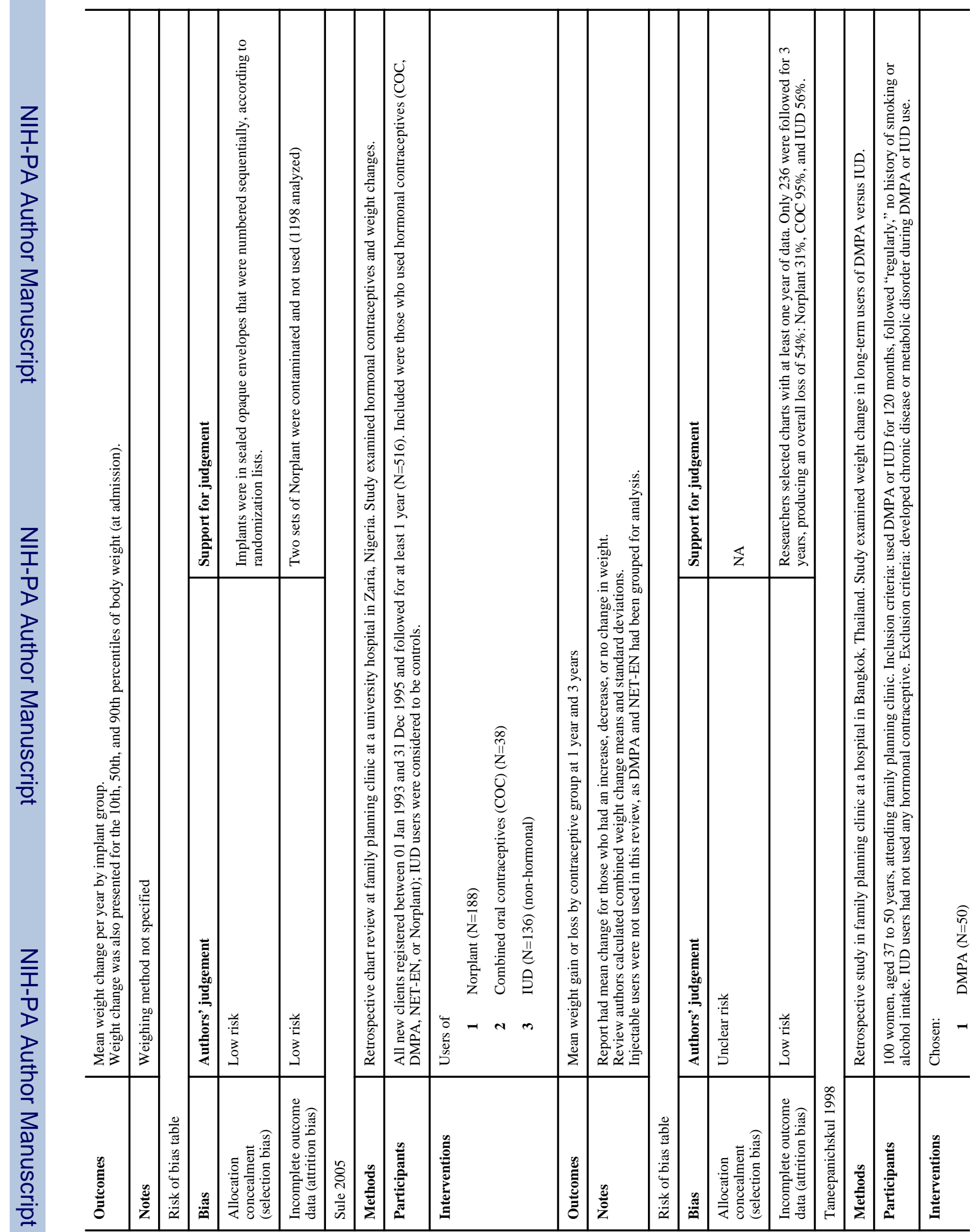




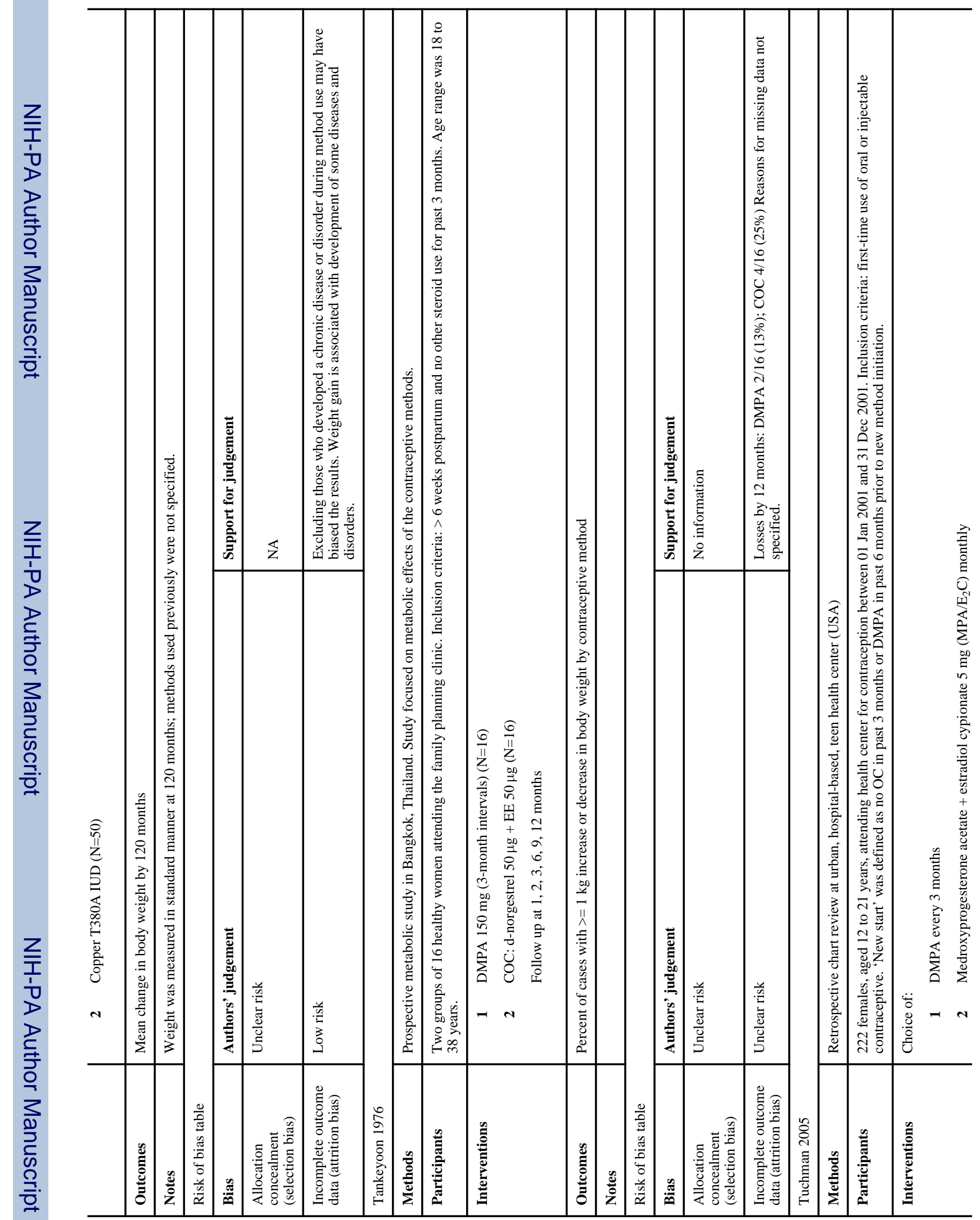




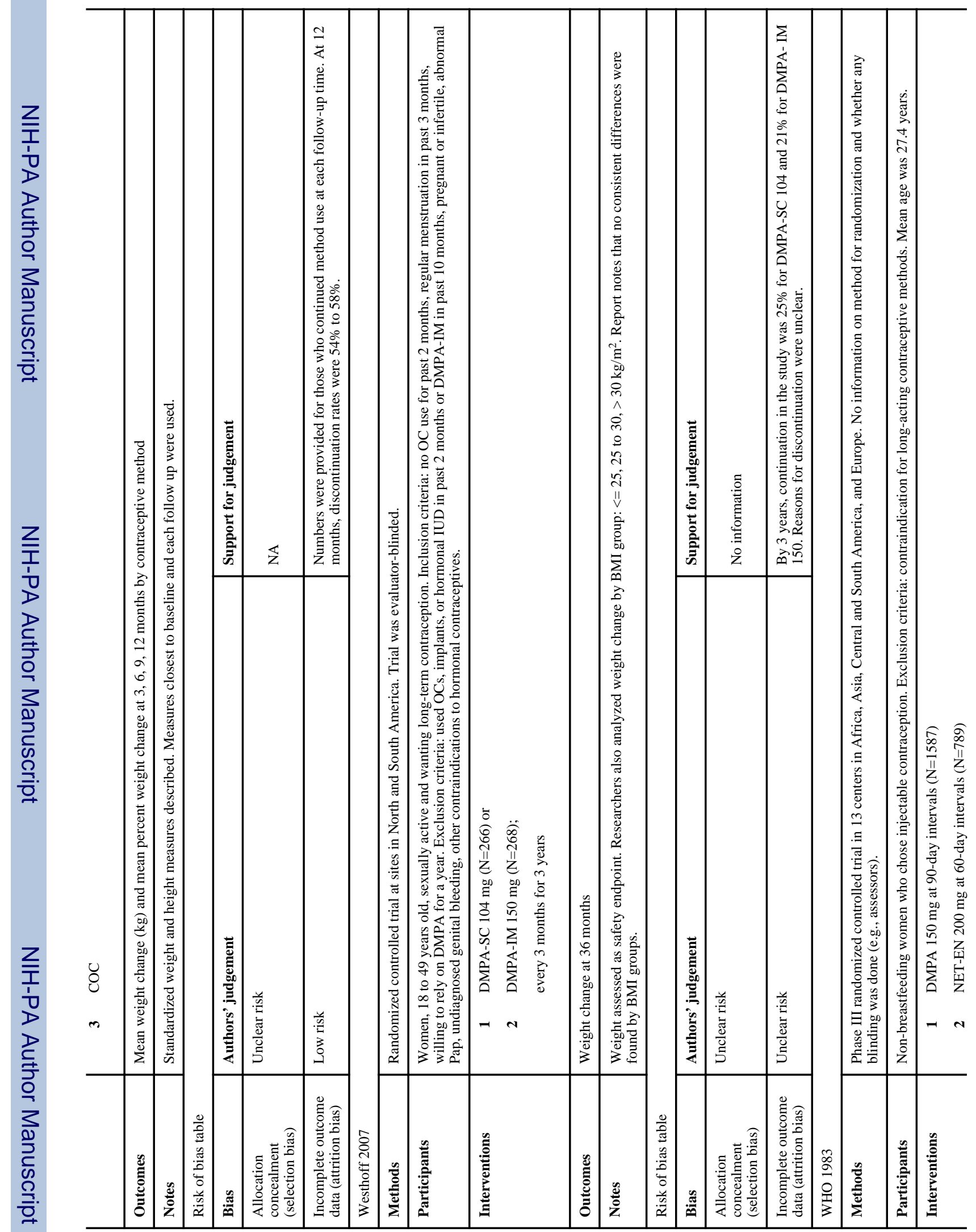




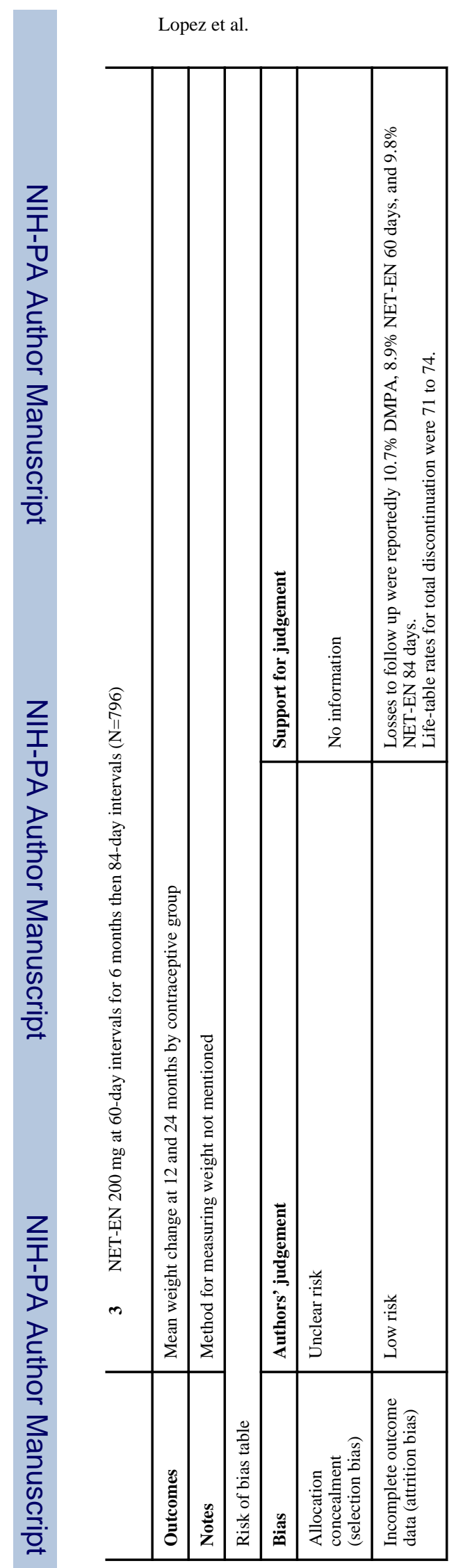

Page 43 
Characteristics of excluded studies

\begin{tabular}{|c|c|}
\hline \multicolumn{2}{|l|}{ Agoestina 1978} \\
\hline Reason for exclusion & $\begin{array}{l}\text { Insufficient weight change data: presented in figure without any specific numbers, other than mean gain for DMPA } \\
\text { group in text. }\end{array}$ \\
\hline \multicolumn{2}{|l|}{ Bahamondes 2010} \\
\hline Reason for exclusion & $\begin{array}{l}\text { Mean weight change not reported. BMI included as control variable for examining bone mineral density. } \\
\text { Study examined weight change among participants who had been using the method (LNG-IUS) for at least } 7 \text { years } \\
\text { before the study. }\end{array}$ \\
\hline \multicolumn{2}{|l|}{ Barsivala 1974} \\
\hline Reason for exclusion & $\begin{array}{l}\text { Insufficient data: study duration not reported (our criteria was }>=3 \text { months); also, authors did not specify whether the } \\
\text { variance reported is standard deviation or standard error. }\end{array}$ \\
\hline \multicolumn{2}{|l|}{ Beksinska 2010} \\
\hline Reason for exclusion & $\begin{array}{l}\text { Analysis combined users of DMPA, NET-EN, or both. Authors noted the subgroups were too small to analyze } \\
\text { separately and that differences in weight gain were not significant. }\end{array}$ \\
\hline \multicolumn{2}{|l|}{ Berenson 1997} \\
\hline Reason for exclusion & Insufficient weight change data: means reported without any variance measure \\
\hline \multicolumn{2}{|l|}{ Berenson 2009} \\
\hline Reason for exclusion & $\begin{array}{l}\text { Insufficient weight change data: mean change reported without any variance. } \\
\text { Of } 240 \text { who chose DMPA, } 182(76 \%) \text { discontinued the method. Of the } 182,68 \text { remained in study }<=2 \text { more years ( } 44 \\
\text { began the COC used in the study and } 24 \text { chose non-hormonal methods). Reportedly, DMPA users who had }>5 \% \\
\text { increase in weight at 6-month visit were more likely to be lost to follow up at the next visit than those who had not } \\
\text { gained weight. } \\
\text { Secondary report (Rahman 2012) provided weight gain (by kg categories) over any 6-month period; therefore, } \\
\text { categories overlapped. }\end{array}$ \\
\hline \multicolumn{2}{|l|}{ Bonny 2006} \\
\hline Reason for exclusion & $\begin{array}{l}\text { Analysis combined groups that received DMPA or DMPA with estradiol supplement; researchers reported the two } \\
\text { DMPA groups did not differ in weight gain. Method discontinuation for DMPA was } 37 \% \text { at } 18 \text { months. } \\
\text { Secondary report (Bonny 2011) used weight change to examine bone mineral density but did not report means or } \\
\text { standard deviations. Data from } 2000 \text { to } 2003 \text {. }\end{array}$ \\
\hline \multicolumn{2}{|l|}{ Chen 2011} \\
\hline Reason for exclusion & $\begin{array}{l}\text { Abstract notes that weight gain was reported as side effect. Wrote to investigator regarding whether weight change } \\
\text { was measured. Unable to obtain further information. }\end{array}$ \\
\hline \multicolumn{2}{|l|}{ Clark 2005} \\
\hline Reason for exclusion & $\begin{array}{l}\text { Insufficient weight change data: means (not mean change) presented in a figure. Text mentions mean change for } \\
\text { DMPA at } 30 \text { months (no variance measure) and that the control group was basically unchanged. Due to } \\
\text { discontinuations of DMPA and initiation of hormonal contraception among controls, the samples sizes were 17\% } \\
\text { (DMPA) and 19\% (controls) of baseline by the last visit. }\end{array}$ \\
\hline \multicolumn{2}{|l|}{ Costa 2012} \\
\hline Reason for exclusion & Mean change in weight was not reported. Participants were 1.5 months post-partum. \\
\hline \multicolumn{2}{|l|}{ Dahlberg 1982} \\
\hline Reason for exclusion & Insufficient weight change data: means reported without any variance measure \\
\hline \multicolumn{2}{|l|}{ El Mahgoub 1980} \\
\hline Reason for exclusion & $\begin{array}{l}\text { Insufficient weight change data: mean change reported without any variance measure. Also, percent that lost or gained } \\
\text { weight was reported, but no specific amount of weight was provided. }\end{array}$ \\
\hline \multicolumn{2}{|l|}{ Hall 1980} \\
\hline Reason for exclusion & $\begin{array}{l}\text { Insufficient weight change data: mean change in 'ideal body weight' shown in figure, except for mean change for } \\
\text { progestin-only group reported in text. }\end{array}$ \\
\hline \multicolumn{2}{|l|}{ Havranek 1972} \\
\hline Reason for exclusion & Insufficient weight data: mean change for one group reported without any variance measure \\
\hline
\end{tabular}


Kaunitz 2009

Reason for exclusion $\quad$ Insufficient weight data. Mean change was reported within adverse event section without any variance measure. Data from 2001 to 2004 .

Mangan 2002

Reason for exclusion $\quad$ Comparison groups were DMPA users and OC users. Types of OC were not specified and might have included progestin-only as well as combination OC.

Olsson 1988

Reason for exclusion $\quad$ Insufficient data for analysis: no N per group for analysis. First-year continuation rate was $59 \%$ for Norplant and $77 \%$ for Norplant-2; methods suggest these were life-table rates.

Ortayli 2001

Reason for exclusion $\quad$ Insufficient data: report does not provide sample sizes used for analysis. Outcome data are from a pilot conducted in 1995 and the main study conducted from 1996 to 1998.

Risser 1999

Reason for exclusion $\quad$ Comparison groups were DMPA users and OC users. Types of OC were not specified and might have included progestin-only as well as combination OC.

Segall-Gutierrez 2012

\begin{tabular}{l|l} 
Reason for exclusion & Single-arm study comparing normal weight and obese women. The one intervention was subcutaneous DMPA.
\end{tabular}

WHO 1978

\begin{tabular}{l|l} 
Reason for exclusion & Insufficient weight data: mean gains reported without any variance measure
\end{tabular}

Yela 2006

Reason for exclusion $\quad$ Insufficient weight change data: tables show weight and BMI means (not change) by year; text mentions mean change per group over 5 years without any variance measure. Study began in 1998.

Zheng 1999

\begin{tabular}{l|l} 
Reason for exclusion & Insufficient weight change data: means reported without any variance measure
\end{tabular} 


\section{Characteristics of studies awaiting classification}

\begin{tabular}{|l|l|}
\hline Madden 2013 & \\
\hline Methods & $\begin{array}{l}\text { Observational, cohort study; non-probability sample. } \\
\text { Purpose: learn whether women who use progestin-only methods will experience weight change compared to women using the } \\
\text { non- hormonal copper IUD. } \\
\text { Primary hypothesis: users of DMPA will gain excess weight and increase their BMI above the copper-IUD users. } \\
\text { Secondarily, compare users' data in LNG-IUD and ENG implant groups to copper-IUD group. }\end{array}$ \\
\hline Participants & $\begin{array}{l}427 \text { women } \\
\text { Inclusion criteria: enrolled in CHOICE between the age 18 and 45 years and consented to future studies; chose } \\
\text { levonorgestrel-releasing IUD, copper IUD, implant, or DMPA as CHOICE baseline method; baseline height and weight data } \\
\text { collected from on-campus enrollment site; able to return to on-campus enrollment site for study activities. } \\
\text { Exclusion criteria: recent history of DMPA use before starting baseline CHOICE method; used current method < 11 months } \\
\text { or > 12 months and 3 weeks. }\end{array}$ \\
\hline Interventions & DMPA, LNG-IUD, copper-T IUD, or implant. \\
\hline Outcomes & Weight change by 12 months \\
\hline Notes & $\begin{array}{l}\text { After the updated review was submitted, the investigator communicated that an article was accepted for publication. Those } \\
\text { results will be add to the next update. Note: Reportedly, the adjusted model indicated no significant difference between the } \\
\text { study arms in weight gain. }\end{array}$ \\
\hline
\end{tabular}


Characteristics of ongoing studies

\begin{tabular}{|c|c|}
\hline \multicolumn{2}{|l|}{ Bonny 2012} \\
\hline Study name & Drug Exposure and Depot Medroxyprogesterone Acetate (DMPA) in Adolescent Subjects \\
\hline Methods & $\begin{array}{l}\text { Randomized, open-label; pharmacokinetic study. Purpose: learn whether DMPA affects weight gain and bone mineral } \\
\text { density in teens. }\end{array}$ \\
\hline Participants & $\begin{array}{l}45 \text { healthy young women } \\
\text { Inclusion criteria: healthy, postmenarchal females. age } 12 \text { to } 21 \text { years; self-selected to initiate DMPA; willingness to } \\
\text { use a barrier method of contraception in addition to DMPA. } \\
\text { Exclusion criteria: chronic disease known to affect weight or bone mineral density (BMD) (e.g. diabetes, kidney); use } \\
\text { of medication known to affect weight or BMD (e.g. corticosteroids); DMPA use in past } 12 \text { months; pregnancy in past } \\
6 \text { months; etonogestrel implant, levonorgestrel-releasing intrauterine system or combined estrogen/progesterone } \\
\text { contraceptive in past } 3 \text { months (OC, patch, vaginal ring); weight > } 250 \text { lbs; need for confidential contraceptive care } \\
\text { for individuals < } 18 \text { years of age. }\end{array}$ \\
\hline Interventions & $\begin{array}{l}\text { DMPA, intramuscular injection } \\
150 \mathrm{mg} \text {; approved for use (US Food and Drug Administration (FDA)) when given into muscle. } \\
104 \mathrm{mg} \text {; FDA-approved for use only when given under the skin; therefore considered experimental. } \\
75 \mathrm{mg} \text {; considered experimental; not FDA-approved regardless of how given. }\end{array}$ \\
\hline Outcomes & $>5 \%$ weight gain at 24 weeks; $>10 \%$ weight gain at 48 weeks. \\
\hline Starting date & Sep 2011. Estimated completion: Dec 2013. \\
\hline Contact information & $\begin{array}{l}\text { Lauren Bird, RN; 614-722-2650; Lauren.Bird@ NationwideChildrens.org } \\
\text { Hannah Lange, MPH; 614-722-3465; Hannah.Lange@ NationwideChildrens.org } \\
\text { Principal Investigator: Andrea Bonny, MD }\end{array}$ \\
\hline \multicolumn{2}{|l|}{ Notes } \\
\hline \multicolumn{2}{|l|}{ Madden 2012b } \\
\hline Study name & $\begin{array}{l}\text { Comparison of Body Composition \&Weight Change in Users of Progestin-only Contraception During the First Year } \\
\text { of Use (DEXA) }\end{array}$ \\
\hline Methods & $\begin{array}{l}\text { Observational prospective cohort; non-probability sample. } \\
\text { Purpose: learn if women gain weight using progestin-only methods of contraception and if so, how much. }\end{array}$ \\
\hline Participants & $\begin{array}{l}345 \text { women } \\
\text { Inclusion criteria: women aged } 18 \text { to } 45 \text { years, starting the copper IUD or implant through their provider, first study } \\
\text { visit must occur within } 14 \text { days of method insertion. } \\
\text { Exclusion criteria: DMPA in past } 16 \text { weeks; POPs, LNG-IUC, or implant in past } 4 \text { weeks; thyroid disease, } \\
\text { autoimmune disease, diabetes (excluding gestational); history of eating disorder; currently taking antidepressants for }< \\
6 \text { months, antipsychotics; oral glucocorticoids (steroids, i.e. prednisone) for }>6 \text { months; currently breastfeeding or }<6 \\
\text { months postpartum. }\end{array}$ \\
\hline Interventions & $\begin{array}{ll}\mathbf{1} & \text { Levonorgestrel-containing intrauterine contraceptive (LNG-IUC) } \\
\mathbf{2} & \text { Etonogestrel (ENG) subdermal implant } \\
\mathbf{3} & \text { Copper IUD. }\end{array}$ \\
\hline Outcomes & $\begin{array}{l}\text { Weight change at } 12 \text { months; compare changes in body weight and BMI. } \\
\text { Body composition assessed with dual-energy x-ray absorptiometry (DEXA); diet and activity via validated } \\
\text { questionnaires. }\end{array}$ \\
\hline Starting date & April 2010; estimated completion Jan 2013 \\
\hline Contact information & $\begin{array}{l}\text { Danielle S Grunloh, BS; 314-747-1425; grunlohd@ wudosis.wustl.edu Tessa E Madden, MD, MPH; Washington } \\
\text { University School of Medicine }\end{array}$ \\
\hline Notes & \\
\hline
\end{tabular}

